Arnott, D.and Pervan, G. "A critical analysis of Decision Support Systems research", Journal of Information Technology, 20, 2, June, 2005, pp67-87. 


\title{
A Critical Analysis of Decision Support Systems Research ${ }^{1}$
}

\author{
David Arnott \\ Monash University \\ Melbourne, Australia \\ Email: david.arnott@infotech.monash.edu.au \\ Graham Pervan \\ Curtin University of Technology \\ Perth, Australia \\ Email: pervang@cbs.curtin.edu.au
}

\section{Abstract}

This paper critically analyses the nature and state of decision support systems (DSS) research. To provide context for the analysis, a history of DSS is presented which focuses on the evolution of a number of sub-groupings of research and practice: personal decision support systems, group support systems, negotiation support systems, intelligent decision support systems, knowledge managementbased DSS, executive information systems/business intelligence, and data warehousing. To understand the state of DSS research an empirical investigation of published DSS research is presented. This investigation is based on the detailed analysis of 1,020 DSS articles published in 14 major journals from 1990 to 2003. The analysis found that DSS publication has been falling steadily since its peak in 1994 and the current publication rate is at early 1990s levels. Other findings include that personal DSS and group support systems dominate research activity and data warehousing is the least published type of DSS. The journal DSS is the major publishing outlet; US 'Other' journals dominate DSS publishing and there is very low exposure of DSS in European journals. Around two-thirds of DSS research is empirical, a much higher proportion than general IS research. DSS empirical research is

\footnotetext{
${ }^{1}$ Acknowledgements: We would like to thank Gemma Dodson for research assistance, especially in obtaining articles and coding, and Peter O'Donnell for discussions about DSS history. The research was partially supported by a Monash University Small Grant and a Curtin University Visiting Professorship. Preliminary results from the empirical study were presented at the 2004 IFIP International Conference on Decision Support Systems, Prato, Italy and the 2004 Australasian Conference on Information Systems, Hobart, Australia.
} 
overwhelming positivist, and is more dominated by positivism than IS research in general. Design science is a major DSS research category. The decision support focus of the sample shows a wellbalanced mix of development, technology, process, and outcome studies. Almost half of DSS papers did not use judgement and decision-making reference research in the design and analysis of their projects and most cited reference works are relatively old. A major omission in DSS scholarship is the poor identification of the clients and users of the various DSS applications that are the focus of investigation. The analysis of the professional or practical contribution of DSS research shows a field that is facing a crisis of relevance. Using the history and empirical study as a foundation, a number of strategies for improving DSS research are suggested.

\section{Keywords}

Decision support systems, group support systems, executive information systems, data warehousing, business intelligence, research.

\section{Introduction}

Decision support systems (DSS) is the area of the information systems (IS) discipline that is focused on supporting and improving managerial decision-making. In terms of contemporary professional practice, DSS includes personal decision support systems, group support systems, executive information systems, online analytical processing systems, data warehousing, and business intelligence. Over the three decades of its history, DSS has moved from a radical movement that changed the way information systems were perceived in business, to a mainstream commercial IT movement that all organizations engage. DSS has continued to be a significant sub-field of IS scholarship.

IS, as an academic discipline, is currently at an important stage of its development. It faces a significant downturn in IT activity in commerce and government, which has led to serious decline in student numbers in IS degree programs. At the same time there is a groundswell of concern about the nature and direction of IS research. These concerns include the object of IS research (Weber, 1987), 
the relevance and rigor of research (Galliers, 1994; Saunders, 1998; Benbasat and Zmud, 1999), and the general place of IS in academe (King and Lyytinen, 2004). An important vehicle in understanding the current state of IS scholarship is the critical analysis of published research (Chen and Hirschheim, 2004). Combined with a reasoned reflection on the discipline, the analysis of quality publications helps understand how IS research can be improved. This paper provides such an analysis for DSS. It is structured as follows: first, a brief history of the DSS field is presented. The history traces its evolution from its radical beginnings to a complex disciplinary structure of partially connected sub-fields. The history provides the context for a critical analysis of published DSS research. The method and design of the literature analysis is described in detail, followed by the presentation and discussion of the analysis findings. Finally, a number of strategies for improving DSS research are suggested.

\section{A Brief History of Decision Support Systems}

In the early 1960s, organizations were beginning to computerise many of the operational aspects of their business. Information systems were developed to perform such applications as order processing, billing, inventory control, payroll, and accounts payable. The goal of the first management information systems (MIS) was to make information in transaction processing systems available to management for decision-making purposes. Unfortunately, few MIS were successful (Ackoff, 1967; Tolliver, 1971). Perhaps the major factor in their failure was that the IT professionals of the time misunderstood the nature of managerial work. The systems they developed tended to be large and inflexible and while the reports generated from managers' MIS were typically several dozen pages

thick, unfortunately, they held little useful management information (Ackoff, 1967; Mintzberg, 1977). The title of Dearden's (1972) Harvard Business Review article, "MIS is a Mirage", summarized the feelings of the time.

The term "decision support systems" first appeared in a paper by Gorry and Scott Morton (1971), although Andrew McCosh attributes the birth date of the field to 1965, when Michael Scott Morton's PhD topic, "Using a computer to support the decision-making of a manager" was accepted by the Harvard Business School (McCosh, 2004). Gorry and Scott Morton (1971) constructed a framework 
for improving management information systems using Anthony's categories of managerial activity (Anthony, 1965) and Simon's taxonomy of decision types (Simon, 1960/1977). Gorry and Scott Morton conceived DSS as systems that support any managerial activity in decisions that are semistructured or unstructured. Keen and Scott Morton (1978) later narrowed the definition, or scope of practice, to semi-structured managerial decisions; a scope that survives to this day. The managerial nature of DSS was axiomatic in Gorry and Scott Morton (1971), and this was reinforced in the field's four seminal books: Scott Morton (1971), McCosh and Scott Morton (1978), Keen and Scott Morton (1978), and Sprague and Carlson (1982).

Much of the early work on DSS was highly experimental, even radical (Alter, 1980; Keen and Gambino, 1983). The aim of early DSS developers was to create an environment in which the human decision maker and the IT-based system worked together in an interactive fashion to solve problems; the human dealing with the complex unstructured parts of the problem, the information system providing assistance by automating the structured elements of the decision situation. The emphasis of this process was not to provide the user with a polished application program that efficiently solved the target problem. In fact, the problems addressed are by definition impossible, or inappropriate, for an IT-based system to solve completely. Rather, the purpose of the development of a decision support system is an attempt to improve the effectiveness of the decision maker. In a real sense, DSS is a philosophy of information systems development and use and not a technology.

DSS is not a homogenous field. There are a number of fundamentally different approaches to DSS and each has had a period of popularity in both research and practice. Each of these "DSS types" represents a different philosophy of support, system scale, level of investment, and potential organisational impact. They can use quite different technologies and may support different managerial constituencies. Figure 1 extends the analysis of Silver (1991, Figure 1.4) and traces the evolution of the field from its radical beginnings to a complex disciplinary structure of partially connected subfields. In the figure, the emphasis is on the theoretical foundations of each DSS type. The decades indicated on the left hand side of the diagram refer only to the DSS types and not to the reference disciplines. Another dimension to the evolution of DSS is improvement in technology, as the 
emergence of each of the DSS types has usually been associated with the deployment of new information technologies. The nature and development of each DSS type is discussed in detail below.

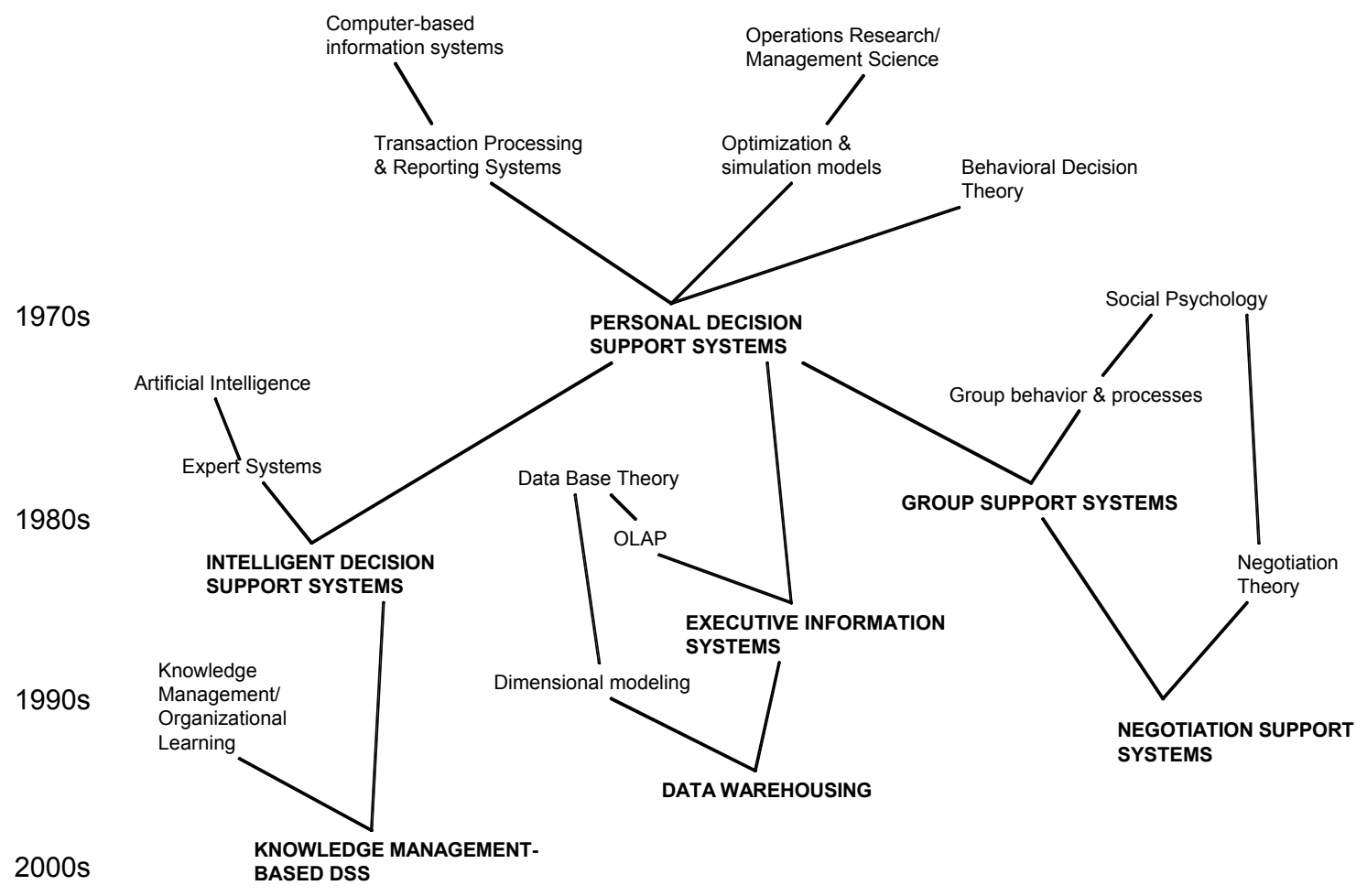

Figure 1: The Evolution of the Decision Support Systems Field

\section{Personal Decision Support Systems}

Personal DSS (PDSS) are small-scale systems that are normally developed for one manager, or a small number of independent managers, for one decision task. PDSS are the oldest form of decision support system and for around a decade they were the only form of DSS in practice. They effectively replaced MIS as the management support approach of choice. The world of MIS was that of the Cold War and the rise of the Multi-National Corporation. The focus of management in this environment was total integration, efficiency, and central control, and the large, inflexible MIS mirrored this organizational environment. The emergence of PDSS also mirrored its social and organizational environment. The 
1960s and 1970s saw a radicalisation of Western society, especially in response to the Vietnam War. The emphasis was on empowering individuals and a democratisation of decision-making. PDSS followed this philosophy by supporting individual managers rather than attempting to support the more nebulous concept of 'the organization'. An important difference between MIS and PDSS was that PDSS were successful systems (Alter, 1980).

The major contribution of PDSS to IS theory is evolutionary systems development (Arnott, 2004). The notion that a DSS evolves through an iterative process of systems design and use has been central to the theory of decision support systems since the inception of the field. Evolutionary development in decision support was first hinted at by Meador and Ness (1974) and Ness (1975) as part of their description of middle-out design. This was a response to the top-down versus bottom-up methodology debate of the time concerning the development of transaction processing systems. Courbon et al. (1978) provided the first general statement of DSS evolutionary development. In what they termed an "evolutive approach", development processes are not implemented in a linear or even in a parallel fashion, but in continuous action cycles that involve significant user participation. As each evolutive cycle is completed the system gets closer to its final or stabilised state. Keen (1980), building on Courbon's work, developed a framework or model for understanding the dynamics of decision support systems evolution. The approach proposed by Keen, shown in Figure 2, was termed adaptive design, although adaptive development is a more accurate term, as the approach comprises development processes other than design. The importance of this work was to give the concept a larger audience; Keen (1980) remains the most cited and thereby the most influential description of the evolutionary approach to DSS development. Amongst other contributors to DSS development theory, Sprague and Carlson (1982) defined an evolutionary DSS development methodology, and Silver (1991) extended Keen's approach by considering how DSS restrict or limit decision-making processes. 


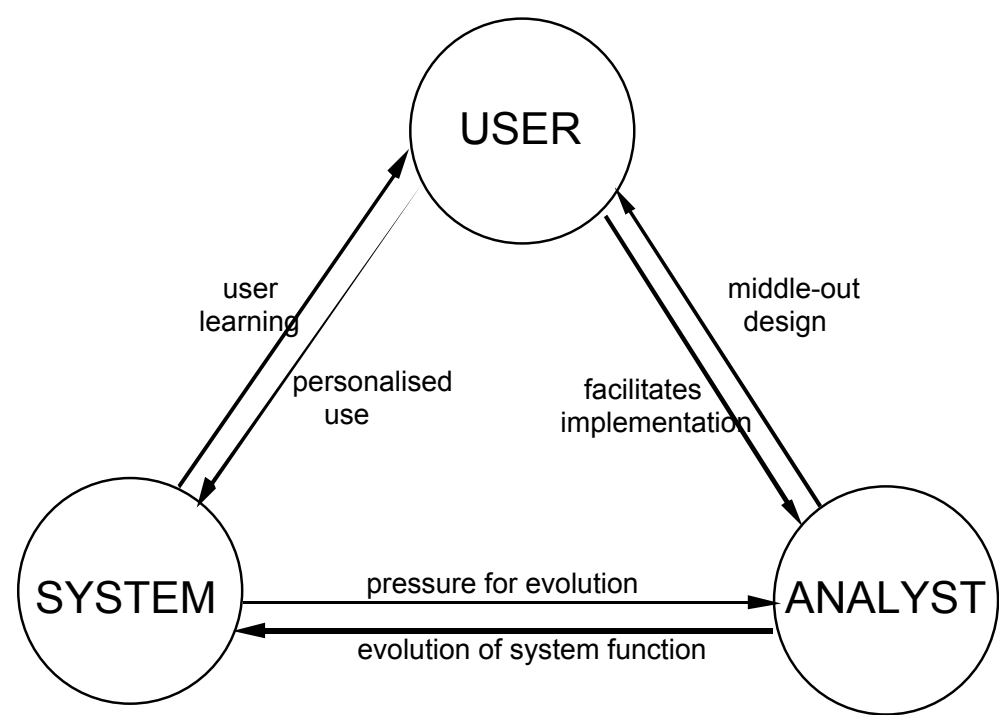

Figure 2. Keen's Adaptive Design Framework

The technology that enabled the development of PDSS was the minicomputer (for example, Digital Equipment Corporation's PDP series) and relatively user-friendly software applications, especially financial modelling and data base software. In the mid 1980s the personal computer and spreadsheet software further drove down the cost of technology and dispersed PDSS through all levels of management. Alter's influential taxonomy of decision support systems (Alter, 1980, chap. 2) illuminates the technical foundation of DSS. Shown in Table 1, it has been widely used in DSS research and textbooks. Although it was formulated in the late 1970s, it remains relevant, as attested by more recent empirical validation (Pearson and Shim, 1994). Although developed for personal DSS, it is very useful for classifying contemporary DSS like business intelligence systems and customer relationship analytics.

\begin{tabular}{|l|l|l|}
\hline \multirow{2}{*}{ Technical Orientation } & System Types & Description \\
\hline \multirow{2}{*}{ Data-oriented } & File Drawer Systems & Allow immediate access to data items \\
\cline { 2 - 3 } & Data Analysis Systems & Allow manipulation of data by tailored or \\
& general operators \\
\cline { 2 - 3 } & Analysis Information Systems & Provide access to a series of databases and \\
\hline
\end{tabular}




\begin{tabular}{|c|c|c|}
\hline & & small models \\
\hline \multirow{4}{*}{ Model-oriented } & Accounting Models & $\begin{array}{l}\text { Calculate the consequences of planned } \\
\text { actions using accounting definitions }\end{array}$ \\
\hline & Representational Models & $\begin{array}{l}\text { Estimate the consequences of actions } \\
\text { without using or partially using } \\
\text { accounting definitions }\end{array}$ \\
\hline & Optimization Models & $\begin{array}{l}\text { Provide guidelines for action by } \\
\text { generating an optimal solution }\end{array}$ \\
\hline & Suggestion Models & $\begin{array}{l}\text { Provide processing support for a } \\
\text { suggested decision for a relatively } \\
\text { structured task }\end{array}$ \\
\hline
\end{tabular}

Table 1. Alter's Taxonomy of Decision Support Systems

PDSS remains an important aspect of IT-based management support in contemporary practice. Modern PDSS can source data from data warehouses and deploy powerful modelling approaches from management science/operations research. The current industry term for the later class of PDSS is 'analytics' (Morris et al., 2003).

\section{Group Support Systems}

In a PDSS an individual manager has power or responsibility for the decision but in a group support system (GSS) decision responsibility is shared by a number of managers and a number of managers need to be involved in the decision process. A GSS "consists of a set of software, hardware, and language components and procedures that support a group of people engaged in a decision-related meeting" (Huber, 1984). This definition can be expanded to include communication and information processing (Kraemer and King, 1988). GSS are typically implemented as electronic meeting systems (EMS) (Dennis et al., 1988) or group decision systems (GDS) (Pervan and Atkinson, 1995). 
Group environments that require the support of GSS can be classified by the time duration of the meetings (either synchronous or asynchronous) or the space occupied by the group (either face to face or dispersed) (DeSanctis and Gallupe, 1985). In the early 1980s, GSS research initially focused on "decision rooms" (synchronous and face to face) such as those facilities established at the University of Arizona (Konsynski et al., 1985), University of Minnesota (DeSanctis and Gallupe, 1985), and Southern Methodist University (Gray et al., 1981). Software to support group work in these decision rooms included Mindsight, Facilitator (now MeetingWorks), Plexsys (now GroupSystems), SAMM and TeamFocus (Wagner, Wynne, and Mennecke, 1993). Over time GSS technologies and research have expanded to include all four categories of the time/space classification through software such as Lotus Notes/Domino (Press, 1992) and now includes such sub-fields as GDS, EMS, CSCW (Computer-Supported Cooperative Work), and CMCS (Computer-Mediated Communication Systems) and are focused on supporting decision makers in a variety of tasks (DeSanctis and Gallupe, 1987).

A number of frameworks have guided GSS research. Figure 3 below shows that the group decisionmaking environment consists of a combination of characteristics of the group (including group history, member proximity, group size, national culture, leadership behaviour, and group cohesiveness), the task (including type of task, level of decision making, phases of decision making, degree of task structure, difficulty, and time synchronisation), the group and organizational context (including corporate culture and behaviour norms, maturity of the organisation, organisational size, time frame of decision making, management style, recognition and reward systems), and the system (EMS, GDS, CSCW). These influence the group process which finally leads to a group outcome (including measures of efficiency, decision quality, group consensus, and satisfaction) (Nunamaker et al., 1991). 


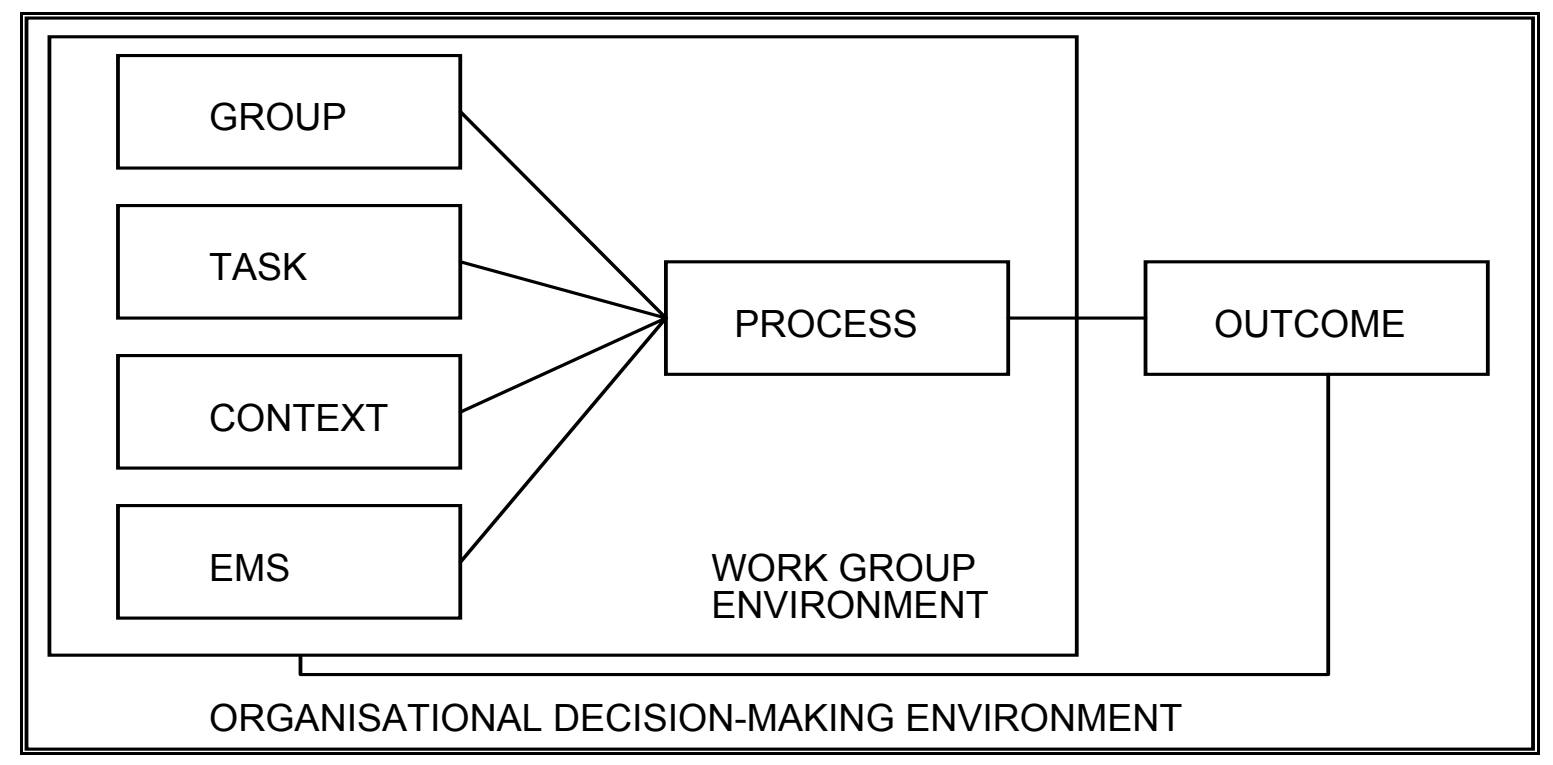

Figure 3. Framework for GSS Research (Nunamaker et al., 1991)

Based on frameworks such as these, GSS researchers have conducted many experiments and a number of field studies which have looked at anonymity, group size, parallelism, process structuring, group development and many of the other characteristics of the GSS environment, as well as investigating theories of decision making, group process theories, communication theory, institutional theory, and coordination theories (Dennis and Gallupe, 1993; McGrath and Hollingshead, 1993).

\section{Negotiation Support Systems}

Negotiation support systems (NSS) also operate in a group context but as the name suggests they involve the application of computer technologies to facilitate negotiations (Rangaswamy and Shell, 1997). As GSS were developed, the need to provide electronic support for groups involved in negotiation problems and processes evolved as a focused sub-branch of GSS with different conceptual foundations to support those needs.

Two approaches to constructing systems that support negotiation arose, namely problem oriented and process oriented (Jelassi, Kersten, and Zionts, 1990). Problem-oriented NSS products include Co-oP (Bui and Jarke, 1986), DECISION MAKER (Fraser and Hippel, 1984), GDSI (Kersten, 1987) and MEDIATOR (Jarke, Jelassi, and Shakun, 1987). These problem-oriented systems focus on providing 
support to support negotiation for specific problem types. On the other hand, process-oriented NSS focus on providing general support of the give-and-take process of negotiation (Chaudhury, 1995; Kersten and Shapiro, 1986).

Negotiation support systems has its conceptual foundations in game theory (Von Neumann and Morgenstern, 1947; Kuhn and Tucker, 1950; Nash, 1950; 1953), which supports many models of bargaining (Raiffa, 1982; Rubinstein, 1982; Bottom and Paese, 1999), and social choice theory (Arrow, 1951; Nurmi, 2001). While NSS may be considered a branch of GSS research, it has evolved using different theories, technologies and applications and now stands as a significant branch of DSS history.

\section{Intelligent Decision Support Systems}

Artificial intelligence (AI) techniques have been applied to decision support and these systems are normally called intelligent DSS or IDSS (Bidgoli, 1998) although the term knowledge-based DSS has also been used (Doukidis, Land, and Miller, 1989). Intelligent DSS can be classed into two generations: the first involves the use of rule-based expert systems and the second generation uses neural networks, genetic algorithms and fuzzy logic (Turban et al., 2005). A fundamental tension exists between the aims of AI and DSS. AI has long had the objective of replacing human decision makers in important decisions, whereas DSS has the aim of supporting rather than replacing humans in the decision task. As a result the greatest impact of AI techniques in DSS has been embedded in the PDSS, GSS or EIS, and largely unknown to managerial users. This is particularly the case in data mining and customer relationship management.

\section{Executive Information Systems and Business Intelligence}

Executive information systems are data-oriented DSS that provide reporting about the nature of an organization to management (Fitzgerald, 1992). Despite the 'executive' title, they are used by all levels of management. EIS were enabled by technology improvements in the mid to late 1980s, especially client server architectures, stable and affordable networks, graphic user interfaces, and 
multidimensional data modelling. This coincided with economic downturn in many OECD countries that resulted in the downsizing phenomenon that decimated middle management. EIS were deployed to help try to manage the leaner reporting structures. The seminal EIS book, Rockart and DeLong (1988), was titled Executive Support Systems, reflecting the decision support heritage. Rockart had earlier contributed what became EIS's major theoretical contribution to general information systems theory, the notion of critical success factors or CSF (Rockart, 1979). CSF are the small number of factors that must go right for an organization, business unit, or individual executive to prosper. If a manager notices from an EIS report that the business is not performing in any critical area, the EIS enables the manager to drill-down through a report hierarchy to discover the possible sources of the variance. The multidimensional view of data, institutionalised as the 'data cube", was the foundation of early EIS vendor offerings like HOLOS and Cognos. This multidimensionality was later codified and described as online analytical processing (OLAP) by Codd, Codd and Salley (1993).

By the mid 1990s EIS had become mainstream and was an integral component of the IT portfolio of any reasonably sized organization. The business intelligence (BI) movement of the late 1990s changed the direction or emphasis of EIS by focusing on enterprise-wide reporting systems although this organizational focus has yet to be widely realized in successful systems. Dashboard-style interfaces and web delivery changed the look and feel of EIS, and the broader measures of balanced score cards (Kaplan and Norton, 1996) displaced some, but not all, of the CSF framework of EIS reporting. Business intelligence (BI) is a poorly defined term and its industry origin means that different software vendors and consulting organizations have defined it to suit their products; some even use 'BI' for the entire range of decision support approaches. We use business intelligence as the contemporary term for both model-oriented and data-oriented DSS that focus on management reporting, that is, BI is a contemporary term for EIS.

\section{Data Warehouses}

The development of large-scale EIS created the need for continuous high quality data about the operations of an organization. The bull market of the 1990s led to a plethora of mergers and 
acquisitions and an increasing globalization of the world economy. Large organizations were faced with significant challenges in maintaining an integrated view of their business. This was the environment of the birth of data warehousing. A data warehouse is simply a set of databases created to provide information to decision makers (Cooper et al., 2000); they provide raw data for user-focussed decision support through PDSS and EIS.

There are two fundamental approaches to data warehouses: enterprise level data warehouses (Inmon and Hackathorn, 1994) and division or department level data marts (Kimball et al. 1998). This architectural debate has raged since the mid 1990s and shows no signs of abating in practice. The major contribution of data warehousing to IS theory is dimensional modelling (Kimball, 1996). Using dimensional models very large data sets can be organised in ways that are meaningful to managers. They are also relatively easy to query and analyse. In this sense, data warehousing provides the large scale IT infrastructure for contemporary decision support. As a result data warehouse development is dominated by central IT departments that have little experience with decision support. A common theme in industry conferences and professional books is the rediscovery of fundamental DSS principles like evolutionary development (Keen, 1997).

\section{Knowledge Management-based Decision Support Systems}

Organisational knowledge management (KM) has received a large amount of attention by executives and academics since the early 1990s. The action taken by organisations to manage what they deem as knowledge is vital in its ability to increase innovation and competitive advantage and support decision-making. KM affects the entire organisation and involves the management of several areas including IT, organisational behaviour, organisational structure, economics and organisational strategy. It can support decision processes and decision makers. Knowledge management as an information systems movement has also had an impact on DSS research with a major conference on the topic being held in 2000 (Carlsson et al., 2000). Questions addressed in this research include (Carlsson and Lundberg, 2000):

- How decision processes and decision makers can be supported through KM? 
- What knowledge technologies are useful to enhance and amplify decision-making.

- How KM concepts can support different decision-making paradigms?

- What determinants and obstacles exist for effective KM support of decision-making?

While much KM research has focused on knowledge creation (Alavi and Leidner, 2001), KM-based decision support technologies can aid knowledge storage, retrieval, transfer and application by supporting individual and organizational memory and inter-group knowledge access (for example, with electronic bulletin boards, knowledge repositories, discussion forums, knowledge directories, expert systems and workflow systems).

\section{The Current State of Decision Support Systems}

Arguably, the premier specialist academic conference on DSS is the biannual IFIP Working Group 8.3 Conference. This conference has been held continuously since 1983 and virtually all leading DSS scholars have presented their ideas in this forum at some time. In 2004 the conference (branded as DSS 2004) was held in Prato, Italy (Meredith et al., 2004). DSS 2004 comprised 86 research papers; Table 2 shows their breakdown according to the DSS types discussed above. Seven articles were classified as not DSS according to the definition adopted by this paper.

\begin{tabular}{|l|r|r|}
\hline DSS Type & No of & \% of DSS \\
& Articles & Articles \\
\hline Personal DSS & 30 & 38.0 \\
\hline Group Support Systems & 9 & 11.4 \\
\hline EIS (includes BI) & 6 & 7.6 \\
\hline Data Warehouse & 4 & 5.1 \\
\hline Intelligent DSS & 10 & 12.7 \\
\hline Knowledge Management-based DSS & 11 & 13.9 \\
\hline Negotiation Support Systems & 6 & 7.6 \\
\hline Many & 3 & 3.8 \\
\hline
\end{tabular}




\begin{tabular}{|l|r|r|}
\hline Total & 79 & 100.0 \\
\hline
\end{tabular}

Table 2: DSS 2004 Papers by DSS Type

Table 2 shows that almost 40 years after the birth of the field, personal DSS, the oldest type of DSS, still dominates the agenda of researchers. Further, it shows that, as suggested by Nobel Laureate Rabindranath Tagore, "the past is always with us". Every type of DSS, regardless of its age and contemporary professional relevance is represented in the conference program. As each new approach to managerial decision support is added to the information systems research and practice portfolio, each older DSS approach remains in play.

What stands out, as a serious concern in Table 2, is the low proportion of EIS/BI/DW papers at $12.7 \%$ of the DSS papers in the program. The low relative frequency in the distribution cannot be explained by novelty, because, as discussed above, they have been mainstream in practice for some time (Devlin and Murphy, 1988; Kimball et al., 1998; NCR, 1998). There are no academically rigorous market statistics for EIS/BI/DW but conversations with senior chief information officers indicate that almost all major commercial expenditure in decision support involves these DSS types. The industry research firm, Meta Group, estimates that the data warehouse market is currently worth US\$25billion (Mills, 2004). IDC, another commercial research firm, believes that data warehousing and business intelligence are central to contemporary IT investment and will remain so for some time (Morris et al., 2003). Even allowing for serious overestimation by the CIOs and the commercial researchers, the distribution of papers at DSS 2004 shows a marked disconnect between the agendas of DSS researchers and senior IT professionals.

The analysis of the IFIP Working Group 8.3 Conference proceedings does not provide a definitive assessment of research in the DSS field, only an insight into work-in-progress at that time. To gain a definitive view, a detailed analysis of DSS publications in high quality journals is needed. Such a detailed analysis is the subject of the next part of this paper.

\section{Literature Analysis Method and Design}


To rigorously investigate the nature of the DSS field we analysed relevant published research. This style of research has appeared under a number of descriptions in the information systems literature including 'review and assessment of research' (Robey, Boudreau and Rose, 2000), 'literature review and analysis' (Alavi and Leidner, 2001), 'survey' (Malone and Crowston, 1994), and the term we adopted, 'literature analysis' (Pervan, 1998).

There have been a number of critical reviews of DSS publication over the life of the field. Sean Eom's series of analyses have used bibliometric approaches, including co-citation analysis, to analyse the intellectual structure of the field (Eom, 1995; 1996; 1999; Eom and Lee, 1990; 1993). Other reviews have examined the content of articles but have concentrated on one aspect of the field; for example, Benbasat and Nault (1990) only examined empirical research, while Pervan (1998) only analysed group support systems. The literature analysis documented in this paper included all sub-groupings, or types, of DSS. It involved the content analysis of each of the 1,020 papers, that is, reading each paper and applying a data collection protocol. This form of data capture is a very labour intensive process but, importantly, it has the advantage that it can illuminate the deep structure of the field in a way that is impossible with citation studies.

\section{Time Frame}

The time period of published research chosen for this project is 1990 to 2003. The start of this analysis period is marked by two much cited reviews: Eom and Lee (1990) and Benbasat and Nault (1990). Both of these reviews covered the DSS field from its inception to the late 1980's. A third review paper focusing on DSS implementation, Alavi and Joachimsthaler (1992), provides a further anchor for the 1990 starting date of our analysis, as does the TIMS/ORSA and National Science Foundation sponsored discipline assessment (Stohr and Konsynski, 1992). The period 1990 to 2003 also marks an interesting period in the development of the information systems discipline as it witnessed a significant growth in the use of non-positivist research methods. In industry, the analysis period saw the deployment of several new generations of DSS, especially the large-scale approaches of EIS, data 
warehousing, and business intelligence. To help identify trends in DSS research we divided the sample into three eras: 1990-1994 (5 years), 1995-1999 (5 years), and 2000-2003 (4 years).

\section{The Article Sample}

The sample of articles analysed is DSS research published between 1990 and 2003 in 14 journals: Decision Sciences (DS); Decision Support Systems (DSS); European Journal of Information Systems (EJIS); Information and Management (I\&M); Information and Organization (I\&O), formerly Accounting, Management and Information Technologies; Information Systems Journal (ISJ); Information Systems Research (ISR); Journal of Information Technology (JIT); Journal of Management Information Systems (JMIS); Journal of Organisational Computing and Electronic Commerce (JOC\&EC); Journal of Strategic Information Systems (JSIS); Group Decision and Negotiation (GD\&N); Management Science (MS); and MIS Quarterly (MISQ).

Previous analyses of information systems research have used a similar sampling approach (Benbasat and Nault, 1990; Alavi and Carlson, 1992; Pervan, 1998). Alavi and Carlson (1992) used eight North American journals for their sample. However, Webster and Watson (2002) have criticised the over emphasis on North American journals in review papers. In response we included four European information systems journals (ISJ, EJIS, JIT, JSIS) in our sample. An alternative approach is to focus on a small number of influential papers (Alavi and Joachimsthaler, 1992) or to aim for a comprehensive sample of all published research in the area including journal papers, book chapters, and quality conference papers (Webster and Watson, 2002). We adopted a large set of journals as a basis of the sample because we believe that this best represents the invisible college of DSS research. The articles were selected electronically by examining key words and titles. A manual check was performed of the table of contents of each issue of each journal. In addition, the text of each potential article for analysis was examined to verify its decision support content. This procedure identified 1,020 DSS papers. Table 3 shows the distribution of these papers by journal as well as identifying the percentage of papers in each journal that were classified as DSS. Overall, $15.38 \%$ of published papers between 1990 and 2003 were in the DSS field. When only the general IS journals are examined, the 
proportion of DSS articles is still a healthy $11.9 \%$. Alternatively, if the journals Management Science and Decision Sciences are removed (as both are generalist journals covering a much wider field of which IS is a relatively small part), the proportion of DSS papers rises to $21.2 \%$. Each of these different measures indicate that DSS is an important part of the IS discipline.

\begin{tabular}{|c|c|c|c|}
\hline Journal & $\begin{array}{r}\text { No of } \\
\text { DSS } \\
\text { Articles } \\
\text { Published }\end{array}$ & $\begin{array}{r}\text { Total No of } \\
\text { Articles } \\
\text { Published }\end{array}$ & $\begin{array}{r}\text { DSS Articles as } \\
\text { a Percentage of } \\
\text { Published } \\
\text { Articles }\end{array}$ \\
\hline Decision Sciences & 63 & 634 & 9.9 \\
\hline Decision Support Systems & 420 & 777 & 54.1 \\
\hline European Journal of Information Systems & 21 & 321 & 6.5 \\
\hline Group Decision and Negotiation & 111 & 290 & 38.3 \\
\hline Information and Management & 94 & 747 & 12.6 \\
\hline Information and Organization & 15 & 155 & 9.7 \\
\hline Information Systems Journal & 15 & 166 & 9.0 \\
\hline Information Systems Research & 33 & 283 & 11.7 \\
\hline Journal of Information Technology & 22 & 352 & 6.3 \\
\hline Journal of Management Information Systems & 77 & 488 & 15.8 \\
\hline Journal of Organizational Computing and Electronic Commerce & 69 & 211 & 32.7 \\
\hline Journal of Strategic Information Systems & 8 & 223 & 3.6 \\
\hline Management Science & 39 & 1,664 & 2.3 \\
\hline MIS Quarterly & 33 & 321 & 10.3 \\
\hline Total & 1,020 & 6,632 & 15.4 \\
\hline
\end{tabular}

Table 3. Article Sample by Journal

\section{Procedure}

The protocol used to code each paper appears in the Appendix. Some papers, termed 'example articles', were selected as being representative of the various article types. To calibrate the coding process, the example articles (shown in Table 8 below) were coded independently and compared. A small number of changes to the initial assessments were made. The remaining articles were then coded 
by the two authors and a research assistant working independently. The time taken to code each article varied considerably, ranging from one hour for large, complex papers, to ten minutes for the straightforward coding of a known paper. In coding each paper the emphasis was on the dominant attribute of each factor for each paper. For consistency, the coding of articles by the research assistant was reviewed by the first author. The coded protocols were entered into an SPSS database for analysis by the second author, who also performed statistical consistency checks on the coding.

\section{Literature Analysis Findings}

\section{General Patterns of DSS Research}

The distribution of articles across journals and time periods is shown in Table 4. It should be immediately observed that the journal Decision Support Systems dominates the sample with $41.2 \%$ of articles. Intuitively, this is the major outlet for publishing DSS research, so this result should come as no surprise. A further $40.6 \%$ of the sample is published in just five journals (GD\&N. I\&M, JMIS, $J O C \& E C$, and $D S$ ) meaning that six journals dominate the sample with well over $80 \%$ of the published DSS papers.

\begin{tabular}{|l|r|r|r|r|r|r|r|r|}
\hline & \multicolumn{2}{|c|}{$1990-1994$} & \multicolumn{2}{|c|}{$1995-1999$} & \multicolumn{2}{c|}{ To00 -2003 } \\
\cline { 2 - 10 } & No of & \% of & No of & \% of & No of & \% of & No of & \% of \\
& Articles & Period & Articles & Period & Articles & Period & Articles & Sample \\
\hline DS & 33 & 8.7 & 20 & 4.7 & 10 & 4.6 & 63 & 6.2 \\
\hline DSS & 136 & 36.0 & 191 & 45.2 & 93 & 42.5 & 420 & 41.2 \\
\hline EJIS & 9 & 2.4 & 9 & 2.1 & 3 & 1.4 & 21 & 2.0 \\
\hline I\&M & 40 & 10.6 & 31 & 7.3 & 23 & 10.5 & 94 & 9.2 \\
\hline I\&O & 5 & 1.3 & 8 & 1.9 & 2 & 0.9 & 15 & 1.5 \\
\hline ISJ & 7 & 1.9 & 5 & 1.2 & 3 & 1.4 & 15 & 1.5 \\
\hline ISR & 16 & 4.2 & 11 & 2.6 & 6 & 2.7 & 33 & 3.2 \\
\hline JIT & 14 & 3.7 & 6 & 1.4 & 2 & 0.9 & 22 & 2.2 \\
\hline JMIS & 30 & 7.9 & 34 & 8.0 & 13 & 5.9 & 77 & 7.5 \\
\hline
\end{tabular}




\begin{tabular}{|l|r|r|r|r|r|r|r|r|}
\hline JOC\&EC & 36 & 9.5 & 25 & 5.9 & 8 & 3.7 & 69 & 6.8 \\
\hline JSIS & 2 & 0.5 & 2 & 0.5 & 4 & 1.8 & 8 & 0.8 \\
\hline GD\&N & 13 & 3.4 & 59 & 13.9 & 39 & 17.8 & 111 & 10.9 \\
\hline MS & 19 & 5.0 & 13 & 3.0 & 7 & 3.2 & 39 & 3.8 \\
\hline MISQ & 18 & 4.8 & 9 & 2.1 & 6 & 2.7 & 33 & 3.2 \\
\hline Total & 378 & 100.0 & 423 & 100.0 & 219 & 100.0 & 1,020 & 100.0 \\
\hline
\end{tabular}

Table 4: Sample by Journal

Table 4 also reveals that DSS publishing has fallen significantly over time. In the 1990-94 period 75.6 DSS papers were published per year in the sample, in the 1995-99 period the number rose to 84.6 per year, but in the 2000-03 period the number of articles per year fell dramatically to 54.7 . However, the number of DSS papers per year in the journal DSS has changed from 27.2 to 38.2 to 18.6 over the same three time periods, so it seems the dominance of this journal is mostly responsible for the overall fall in DSS publications. The discipline share of papers in the journals DS, ISR, JIT, JMIS, MISQ, and $J O C \& E C$ has also fallen over time. The latter is probably due to that particular journal's declining interest in collaboration technology and increasing interest in electronic commerce. However, the declining share in the other journals reflects a decreasing interest in DSS among IS researchers and publishers. As will be shown later, research in group support systems is the second largest DSS category and perhaps a lessening interest in GSS is responsible for much of the overall fall. However, it should be noted that the overall share of papers from the journal GD\&N has increased, so more GSS research may have been directed to $G D \& N$ as this journal became more established. Figure 4 shows the decline in annual DSS publication in graphical format. It indicates that DSS publication peaked in 1994 and, with the exception of 1997, has been in consistent decline until 2003. 


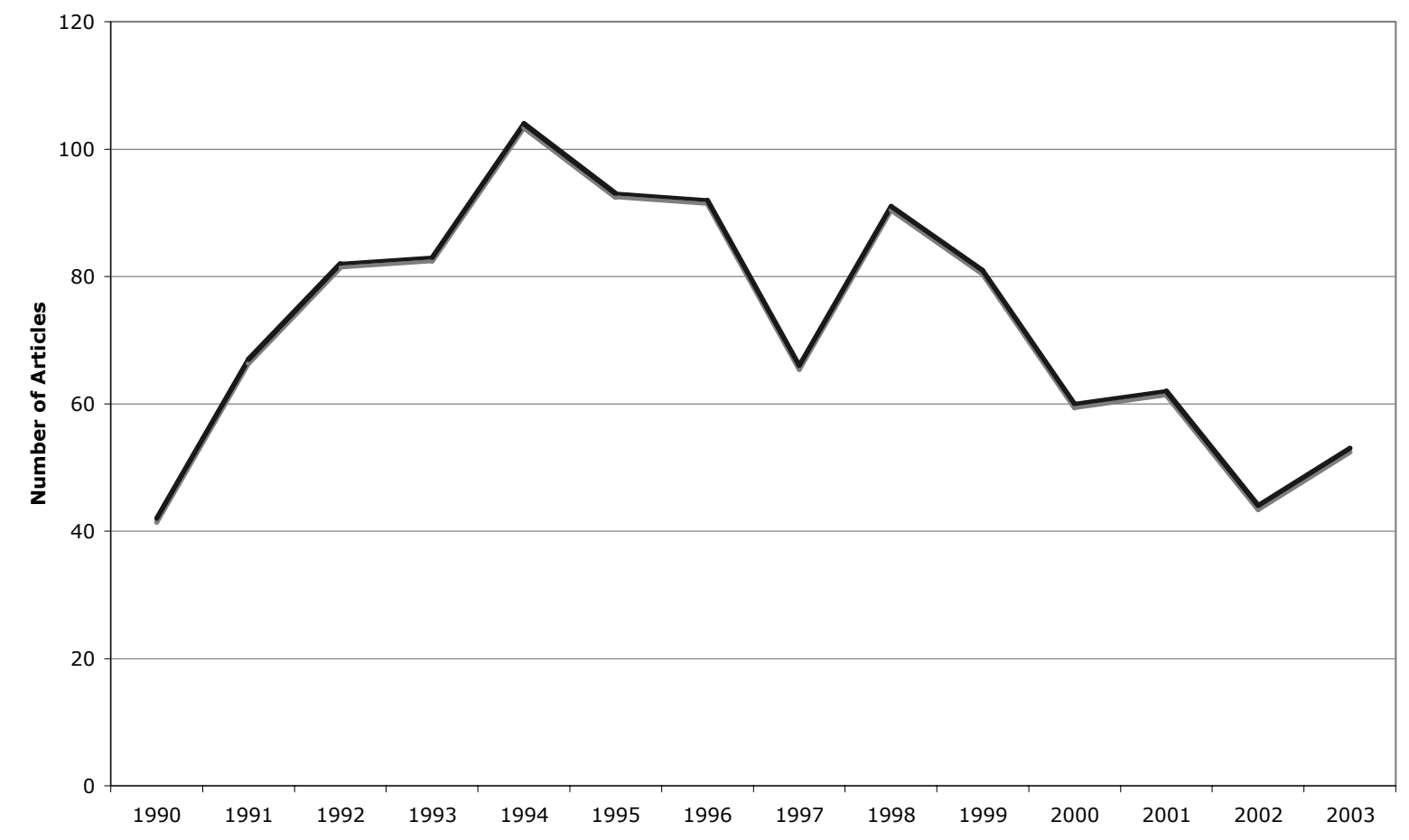

Figure 4. DSS Publishing 1990-2003

To further understand the publishing of DSS research in different journals it was necessary to classify the journals into categories relating to regions and quality. Geographically the journals were classified by their European or United States' origin. Other analyses of IS publishing have found a significant difference between the nature of research published in North American and European journals (Chen and Hirschheim, 2004; Lowry, Romans, and Curtis, 2004). The quality of journals was classified as 'A' level or 'Other'. This classification was based on a number of publications that address journal ranking (Gillenson and Stutz, 1991; Holsapple et al., 1994; Hardgrave and Walstrom, 1997; Mylonopoulos and Theoharakis, 2001; Walstrom et al., 1995; Whitman et al., 1999) and on discussions with a number of journal editors. The overall journal classification scheme used in this paper is shown in Table 5. It should be noted that all of the journals in our sample are high quality; all have a low acceptance rate relative to submissions, all have editorial boards of leading researchers, and all are publishing targets of choice for senior IS researchers. 


\begin{tabular}{|l|l|}
\hline Group & Journals \\
\hline US ‘A' & DS, ISR, MISQ, MS \\
\hline US ‘Other' & DSS, GD\&N, I\&M, I\&O, JMIS, JOC\&EC \\
\hline Europe ‘A' & EJIS, ISJ \\
\hline Europe ‘Other' & JIT, JSIS \\
\hline
\end{tabular}

Table 5: Journal Classification

\begin{tabular}{|l|r|r|r|r|r|r|r|r|}
\hline Journal Class & \multicolumn{2}{|c|}{$1990-1994$} & \multicolumn{2}{|c|}{$1995-1999$} & \multicolumn{2}{|c|}{2000 -2003 } & \multicolumn{2}{c|}{ Total } \\
\cline { 2 - 9 } & No of & \% of & No of & \% of & No of & \% of & No of & \% of \\
& Articles & Period & Articles & Period & Articles & Period & Articles & Sample \\
\hline US ‘A' & 86 & 22.8 & 53 & 12.5 & 29 & 13.2 & 168 & 16.5 \\
\hline US 'Other' & 260 & 66.8 & 348 & 82.3 & 178 & 81.3 & 786 & 77.1 \\
\hline Europe 'A' & 16 & 4.2 & 14 & 3.3 & 6 & 2.7 & 36 & 3.5 \\
\hline Europe 'Other' & 16 & 4.2 & 8 & 1.9 & 6 & 2.7 & 30 & 2.9 \\
\hline Total & 378 & 100.0 & 423 & 100.0 & 219 & 100.0 & 1,020 & 100.0 \\
\hline
\end{tabular}

Table 6: Sample by Journal Classification

The papers in the sample were then divided and grouped into the four categories and Table 6 above presents the publication rates in the four groups, both in total and over the three time periods, while Figure 5 shows the publications in the four categories in each year from 1990 to 2003. While the US 'A' journals have published a reasonable amount of DSS research $(16.5 \%)$, the sample is clearly dominated by US 'Other' journals with $77.1 \%$ of the publications, and most of these occur in GD\&N, $I \& M, J M I S$, and $J O C \& E C$. Figure 3 also shows that the general decline in DSS publication occurs in every class of journal. 


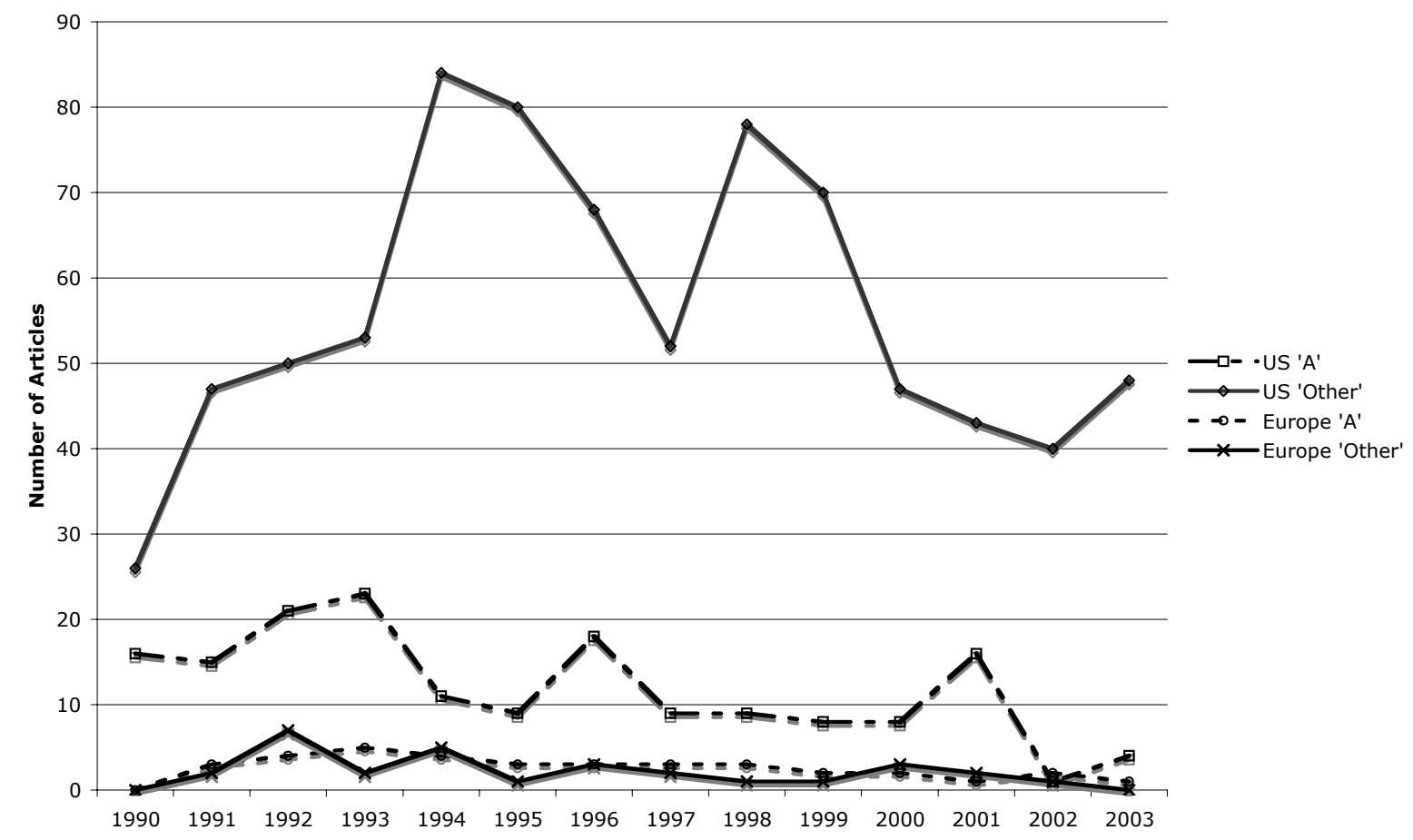

Figure 5. Publication in Classes of Journal

A major finding with respect to journals is that the European journals have a surprisingly low DSS publication rate. Only $6.4 \%$ of the sample is published in European journals, split relatively evenly between European 'A' and 'Other'. Examination of the individual European journals (see Table 4) shows that EJIS, ISJ and JSIS have seldom published DSS research, and while JIT published a reasonably significant number of DSS papers in the1990-94 period, that number has declined recently.

\section{Types of Decision Support Systems}

The article sample was analysed according to the DSS types identified in the history of DSS section. Table 7 shows that the research is mainly focused in four areas: personal DSS, group support systems, intelligent DSS, and large data centred systems (EIS and data warehouses). Personal DSS and intelligent DSS are declining in attention while data warehousing, knowledge management-based DSS, and negotiation support systems are increasing significantly, although data warehousing and knowledge management-based DSS have very low exposure in major journals. This may be a factor in the professional relevance findings discussed later. 


\begin{tabular}{|c|c|c|c|c|c|c|c|c|}
\hline & $\begin{array}{r}\text { No of } \\
\text { Articles }\end{array}$ & $\begin{array}{r}\% \text { of } \\
\text { Period }\end{array}$ & $\begin{array}{r}\text { No of } \\
\text { Articles }\end{array}$ & $\begin{array}{r}\text { \% of } \\
\text { Period }\end{array}$ & $\begin{array}{r}\text { No of } \\
\text { Articles }\end{array}$ & $\begin{array}{r}\text { \% of } \\
\text { Period }\end{array}$ & $\begin{array}{r}\text { No of } \\
\text { Articles }\end{array}$ & $\begin{array}{r}\% \text { of } \\
\text { Sample }\end{array}$ \\
\hline Personal DSS & 144 & 38.1 & 150 & 35.5 & 66 & 30.1 & 360 & 35.3 \\
\hline Group Support Systems & 108 & 28.6 & 126 & 29.8 & 64 & 29.2 & 298 & 29.2 \\
\hline EIS (includes BI) & 27 & 7.1 & 32 & 7.6 & 15 & 6.8 & 74 & 7.3 \\
\hline Data Warehouse & 0 & 0.0 & 2 & 0.5 & 11 & 5.0 & 13 & 1.3 \\
\hline Intelligent DSS & 63 & 16.7 & 61 & 14.4 & 23 & 10.5 & 147 & 14.4 \\
\hline Knowledge Mgt-based DSS & 3 & 0.8 & 6 & 1.4 & 12 & 5.5 & 21 & 2.1 \\
\hline Negotiation Support Systems & 6 & 1.6 & 18 & 4.3 & 17 & 7.8 & 41 & 4.0 \\
\hline Many & 27 & 7.1 & 28 & 6.6 & 11 & 5.0 & 66 & 6.5 \\
\hline Total & 378 & 100.0 & 423 & 100.0 & 219 & 100.0 & 1,020 & 100.0 \\
\hline
\end{tabular}

Table 7: Sample by DSS Type

Figure 6 shows graphically the pattern of publication of the different DSS types over time. The figure is somewhat crowded but it does clarify the importance of personal DSS and GSS to the work of DSS academics. It also 'graphically' highlights the very low publishing levels in EIS and data warehousing. 


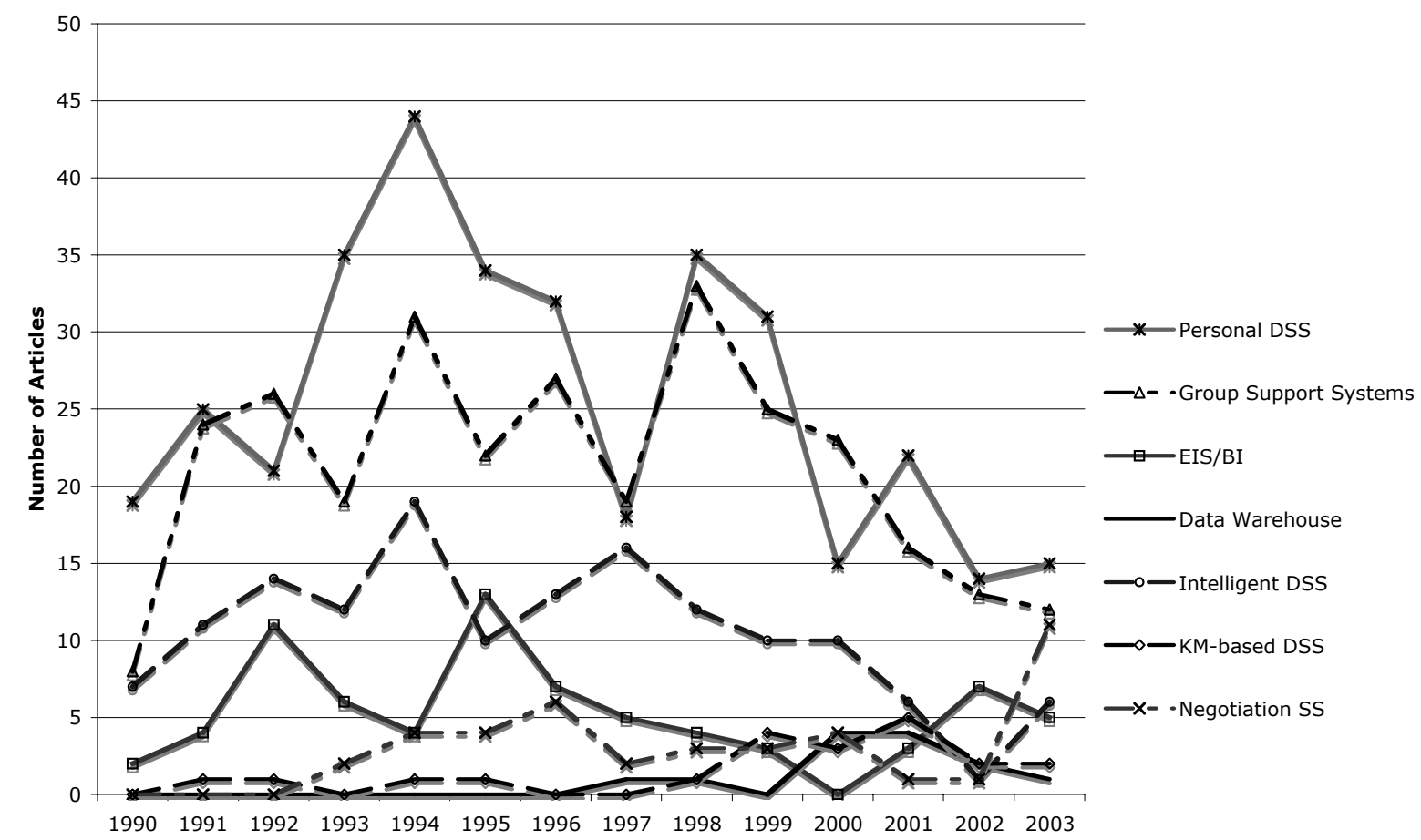

Figure 6. DSS Type Publication by Year

As indicated earlier in Table 4, the journal Decision Support Systems is clearly the major publication outlet for DSS research. A further examination of these publication outlets against the type of DSS revealed that:

$>$ Decision Science publishes mostly personal DSS papers (52.4\% of published DSS papers) and intelligent DSS (27\%).

$>$ Decision Support Systems publishes mostly PDSS (47.1\%), IDSS (23.1\%), and GSS (13.1\%).

$>$ Information and Management publishes mostly PDSS (35.1\%), GSS (31.9\%), and EIS (11.7\%), as does Information Systems Research.

> Journal of Management Information Systems publishes mostly GSS (58.4\%) and PDSS $(14.3 \%)$.

$>$ Journal of Organizational Computing and Electronic Commerce publishes mostly GSS (73.9\%) and PDSS (13\%), though over time its emphasis on GSS research has declined a little.

Group Decision and Negotiation publishes mostly GSS (57.7\%) and NSS (32.4\%), and is almost the sole outlet for the latter with 36 of the 41 NSS articles in the sample.

$>$ MIS Quarterly publishes mostly GSS (39.4\%), EIS (21.2\%), and PDSS (21.2\%). 
The number of DSS articles published in most of the other journals was too few to demonstrate any particular emphasis, though a third of the 15 JIT articles were on EIS.

The overall publication patterns show that GSS and PDSS are broadly published in many journals, intelligent DSS research is seen mostly in DS and DSS, NSS is the most narrowly published (almost entirely in $G D \& N$ ), EIS has key outlets in $D S S$, ISJ, JIT and $M I S Q$, while data warehousing is hardly published anywhere at all. The publication patterns of the other DSS types is mixed.

\section{Research Paradigms}

The period of analysis, 1990 to 2003, saw a significant move in general information systems research towards interpretivism (Orlikowski and Baroudi, 1991; Walsham, 1995b; Cavaye, 1996) and to a lesser extent, critical theory (Hirschheim, 1992). A major consequence of this paradigmatic trend was the rise of the case study as a major research strategy in information systems (Walsham, 1995a). The movement to a more complex and sophisticated disciplinary structure also occurred in social science in general (Guba and Lincoln, 1994). Table 8 shows the empirical papers in the sample coded for research paradigm. DSS research is overwhelmingly dominated by the positivist paradigm with $92.2 \%$ of empirical studies following that approach. Chen and Hirschheim's (2004) study of IS research from 1991 to 2001 reported that $81 \%$ of papers had a positivist orientation with $19 \%$ using an interpretivist approach. This means that DSS research is more dominated by positivism than general IS research. This finding is contrary to accepted opinion on DSS. For example, Iivari (1991) in a much cited analysis of the paradigmatic base of a number of IS schools, identified DSS as the only school with strong post-positivist tendencies. This opinion, formed at the start of this project's time period, is not supported by our data. Examination of the temporal trends in Table 8 shows that interpretivism in DSS research is gradually expanding from its very low base.

\begin{tabular}{|l|r|r|r|r|r|r|r|r|}
\hline Paradigm & \multicolumn{2}{|c|}{$1990-1994$} & \multicolumn{2}{|c|}{$1995-1999$} & \multicolumn{2}{|c|}{2000 -2003 } & \multicolumn{2}{c|}{ Total } \\
\cline { 2 - 8 } & No of & \% of & No of & \% of & No of & \% of & No of & \% of \\
& Articles & Period & Articles & Period & Articles & Period & Articles & Articles \\
\hline Positivist & 217 & 93.5 & 254 & 92.0 & 146 & 90.7 & 617 & 92.2 \\
\hline
\end{tabular}




\begin{tabular}{|l|r|r|r|r|r|r|r|r|}
\hline Interpretivist & 15 & 6.5 & 21 & 7.6 & 15 & 9.3 & 51 & 7.6 \\
\hline Mixed & 0 & 0.0 & 1 & 0.4 & 0 & 0.0 & 1 & 0.1 \\
\hline Total & 232 & 100.0 & 276 & 100.0 & 161 & 100.0 & 669 & 100.0 \\
\hline
\end{tabular}

Table 8: Empirical Articles by Research Paradigm

Table 9 shows the research paradigms adopted by researchers studying the various types of DSS.

What is most interesting in the table is the identification of those types who are embracing interpretivism. Data warehousing (27.3\%) and EIS (17.2\%) have the highest proportion of interpretivist studies, while intelligent DSS (1.3\%) and personal DSS (2.9\%) have almost ignored nonpositivist paradigms. This cannot be explained by differences in the focus of research, units of analysis, and research questions as evidenced by the discussion of other findings in this paper. It is interesting that the more modern types of DSS are being researched with a more modern mix of paradigms than older types of DSS.

\begin{tabular}{|l|r|r|r|r|r|r|r|}
\hline & \multicolumn{2}{|c|}{ Positivist } & \multicolumn{2}{c|}{ Interpretivist } & \multicolumn{2}{c|}{ Mixed } & Total \\
& No of & \% of & No of & \% of & No of & \% of & No of \\
& Articles & Type & Articles & Type & Articles & Type & Articles \\
\cline { 2 - 7 } & 233 & 96.7 & 7 & 2.9 & 1 & 0.4 & 241 \\
\hline Personal DSS & 191 & 88.0 & 26 & 12.0 & 0 & 0.0 & 217 \\
\hline Group Support Systems & 48 & 82.8 & 10 & 17.2 & 0 & 0.0 & 58 \\
\hline EIS (includes BI) & 8 & 72.7 & 3 & 27.3 & 0 & 0.0 & 11 \\
\hline Data Warehouse & 77 & 98.7 & 1 & 1.3 & 0 & 0.0 & 78 \\
\hline Intelligent DSS & 13 & 86.7 & 2 & 13.3 & 0 & 0.0 & 15 \\
\hline Knowledge Mgt-based DSS & 16 & 94.1 & 1 & 5.9 & 0 & 0.0 & 17 \\
\hline Negotiation Support Systems & 31 & 96.9 & 1 & 3.1 & 0 & 0.0 & 32 \\
\hline Many & 617 & 92.2 & 51 & 7.6 & 1 & 0.1 & 669 \\
\hline Total & & & & & & & \\
\hline
\end{tabular}

Table 9: DSS Types by Research Paradigm

\section{Stages of the Research Cycle}


Galliers (1992) proposed a framework (based on Dubin (1978)) for understanding research and its interaction with theory by conceptualising the research process as a cycle of theory building, theory testing, and theory refinement. Table 10 shows the sample by the dominant stage in Galliers' research cycle. It shows that DSS research is dominated by theory building. This is surprising given DSS field's 30 or more-year history. It could be expected that theory testing and refinement would now have a much greater focus. In the sample, theory testing has significantly expanded over time, albeit from a low base. An explanation for the statistics could come from the development of new DSS movements, especially EIS, data warehousing, and business intelligence. Each new decision support movement has required significant theorising and this may keep the theory building percentage of research high in the sample.

\begin{tabular}{|c|c|c|c|c|c|c|c|c|}
\hline \multirow[t]{2}{*}{ Research Stage } & \multicolumn{2}{|c|}{$1990-1994$} & \multicolumn{2}{|c|}{$1995-1999$} & \multicolumn{2}{|c|}{$2000-2003$} & \multicolumn{2}{|c|}{ Total } \\
\hline & $\begin{array}{r}\text { No of } \\
\text { Articles }\end{array}$ & $\begin{array}{r}\text { \% of } \\
\text { Period }\end{array}$ & $\begin{array}{r}\text { No of } \\
\text { Articles }\end{array}$ & $\begin{array}{r}\text { \% of } \\
\text { Period }\end{array}$ & $\begin{array}{r}\text { No of } \\
\text { Articles }\end{array}$ & $\begin{array}{r}\text { \% of } \\
\text { Period }\end{array}$ & $\begin{array}{r}\text { No of } \\
\text { Articles }\end{array}$ & $\begin{array}{r}\text { \% of } \\
\text { Sample }\end{array}$ \\
\hline Theory Building & 267 & 70.6 & 275 & 65.0 & 135 & 61.6 & 677 & 66.4 \\
\hline Theory Testing & 73 & 19.3 & 116 & 27.4 & 70 & 32.0 & 259 & 25.4 \\
\hline Theory Refinement & 14 & 3.7 & 14 & 3.3 & 6 & 2.7 & 34 & 3.3 \\
\hline Unclear & 24 & 6.3 & 18 & 4.3 & 8 & 3.7 & 50 & 4.9 \\
\hline Total & 378 & 100.0 & 423 & 100.0 & 219 & 100.0 & 1,020 & 100.0 \\
\hline
\end{tabular}

Table 10: Sample by Dominant Research Stage

\section{Research Methods and Article Types}

There are a number of different approaches to classifying the type of research in addition to paradigm and stage of research. The approach used in this project is that used by Pervan (1998) in his analysis of published group support systems research. Pervan's taxonomy was based on Alavi and Carlson (1992). The article type taxonomy and the distribution of papers are shown in Table 11. Also provided in the table is an example of each article type. 
Table 11 shows that around one-third (33.6\%) of DSS research is non-empirical, with two-thirds (66.4\%) empirical. Chen and Hirschheim's (2004) analysis of overall IS research reported a significantly different split between non-empirical (40\%) and empirical (60\%). This means that DSS research has significantly more empirical research than general IS. The high $18.4 \%$ figure for the category "Description of Specific Application, System etc" is particularly interesting. As discussed above, DSS was founded with the development of experimental systems for managers. As a result, it has a long history of the publication of descriptions of DSS applications that are novel or important, part of what is now called design science (Hevner et al., 2004). These are not case studies in the sense of Yin (1994) and Eisenhart (1989); there is no explicit theory being tested or being developed by reflecting on the case. As a result, the low combined positivist and interpretivist case study percentage of $8.4 \%$ is lower than would be expected in IS research.

\begin{tabular}{|c|c|c|c|c|c|}
\hline \multirow{9}{*}{ Non-Empirical } & \multicolumn{2}{|l|}{ Article Type } & Number & $\%$ & Example Article \\
\hline & \multirow[t]{4}{*}{ Conceptual } & DSS Frameworks & 47 & 4.6 & Stanek and Sroka (2001) \\
\hline & & Conceptual Models & 26 & 2.5 & Datta and Thomas (1999) \\
\hline & & Conceptual Overview & 48 & 4.7 & Shim et al. (2002) \\
\hline & & Theory & 21 & 2.1 & Powell and Johnson (1995) \\
\hline & \multirow[t]{3}{*}{ Illustrative } & Opinion and Example & 21 & 2.1 & Kendall (1997) \\
\hline & & $\begin{array}{l}\text { Opinion and Personal } \\
\text { Experience }\end{array}$ & 4 & 0.4 & Lewis, Keleman and Garcia (1996) \\
\hline & & $\begin{array}{l}\text { Tools, Techniques, } \\
\text { Methods, Model } \\
\text { Applications }\end{array}$ & 112 & 11.0 & Basu and Blanning (1994) \\
\hline & Applied Concepts & $\begin{array}{l}\text { Conceptual Frameworks } \\
\text { and Their Application }\end{array}$ & 63 & 6.2 & Wood and Wood-Harper (1993) \\
\hline \multirow[t]{12}{*}{ Empirical } & \multirow[t]{2}{*}{ Objects } & $\begin{array}{l}\text { Description of Type or } \\
\text { Class of Product, } \\
\text { Technology, Systems etc. }\end{array}$ & 34 & 3.3 & Chen (1995) \\
\hline & & $\begin{array}{l}\text { Description of Specific } \\
\text { Application, System etc. }\end{array}$ & 188 & 18.4 & Linton and Johnston (2000) \\
\hline & \multirow[t]{10}{*}{ Events/Processes } & Lab Experiment & 186 & 18.2 & Todd and Benbasat (1991) \\
\hline & & Field Experiment & 16 & 1.6 & Benbunan-Fich et al. (2002) \\
\hline & & Field Study & 36 & 3.5 & Vandenbosch and Huff (1997) \\
\hline & & Positivist Case Study & 53 & 5.2 & Cooper et al. (2000) \\
\hline & & Interpretivist Case Study & 32 & 3.1 & Nandhakumar (1996) \\
\hline & & Action Research & 7 & 0.7 & Kock (1998) \\
\hline & & Survey & 69 & 6.8 & Wixom and Watson (2001) \\
\hline & & $\begin{array}{l}\text { Development of DSS } \\
\text { Instrument }\end{array}$ & 4 & 0.4 & Davison (1999) \\
\hline & & Secondary Data & 25 & 2.5 & Alavi and Joachimsthaler (1992) \\
\hline & & Simulation & 28 & 2.7 & Karim et al. (1998) \\
\hline
\end{tabular}

Table 11. Sample by Article Type

\section{Decision Support Focuses}


Another way of classifying a DSS is by the unit of analysis of the research. The unit of analysis specifies the decision support focus of the research project and is usually guided by the reference theories and previous domain research used by the researchers. Table 12 shows that the decision support focus of the papers was reasonably spread across system development, information technology, the impact of the systems on the organization, and the decision-making process. Over time, researcher focus on development and technology has declined and research with a focus on decision outcome and organizational impact has doubled. Intuitively, this mirrors the increasing organizational and social focus of IS research in general.

\begin{tabular}{|l|r|r|r|r|r|r|r|r|}
\hline \multirow{2}{*}{ Decision Support Focus } & \multicolumn{2}{|c|}{$1990-1994$} & \multicolumn{2}{|c|}{$1995-1999$} & \multicolumn{2}{c|}{2000 -2003 } & \multicolumn{2}{c|}{ Total } \\
\cline { 2 - 9 } & No of & \% of & No of & \% of & No of & \% of & No of & \% of \\
& Articles & Period & Articles & Period & Articles & Period & Articles & Sample \\
\hline Systems Development & 87 & 23.0 & 100 & 23.6 & 40 & 18.3 & 227 & 22.3 \\
\hline Information Technology & 101 & 26.7 & 101 & 23.9 & 41 & 18.7 & 243 & 23.8 \\
\hline Decision Outcome/Org Impact & 43 & 11.4 & 73 & 17.3 & 56 & 25.6 & 172 & 16.9 \\
\hline Decision-making Process & 79 & 20.9 & 73 & 17.3 & 42 & 19.2 & 194 & 19.0 \\
\hline Many & 58 & 15.3 & 70 & 16.5 & 34 & 15.5 & 162 & 15.9 \\
\hline Unclear & 10 & 2.6 & 6 & 1.4 & 6 & 2.7 & 22 & 2.2 \\
\hline Total & 378 & 100.0 & 423 & 100.0 & 219 & 100.0 & 1,020 & 100.0 \\
\hline
\end{tabular}

Table 12: Sample by Decision Support Focus

\section{The Relevance of DSS Research}

Any professionally focused academic area (like DSS) needs a reasonable balance between theory development and application since research and practice inform each other. A number of information systems researchers are concerned that there is a widening gap between research and practice, particularly in the systems development area (Galliers, 1994; Saunders, 1998). Fitzgerald (2000) argues that most current systems development methodologies are based on concepts developed in the period 1967 to 1977 . He also argues that changes in the organisational and technical environment since that period have been so great that these methodologies need fundamental review and believes 
that professional practice is currently leading theory in the development methodology area. This has usually been the case but the divergence is probably greater now than at any other time. Benbasat and Zmud (1999) identified five reasons why information systems research lacks relevance. The first is an emphasis of rigor over relevance in order to gain the respect of other academic disciplines; the second is the lack of a cumulative tradition that yields strong theoretical models that act as a foundation for practical prescription; the third is the dynamism of information technology, which means that practice inevitably leads theory; the fourth is a lack of exposure of IS academics to professional practice; and the fifth is the institutional and political structure of universities which limits the scope of action of IS academics. DSS research, as a key part of IS research, is likely to be subject to all five forces.

The assessment of the practical relevance of a journal paper is a subjective judgement. In judging relevance we were informed by the aims and objectives of the paper, the nature of the discussion, and in particular, the content of the concluding comments of each paper. The researchers spent considerable time in discussing and reviewing their coding of this factor to assist in calibrating the independent coding processes.

Table 13 shows that overall, only $9.6 \%$ of research is regarded as having high or very high practical relevance. On the other hand, $50.5 \%$ of research was regarded as having no or low practical relevance. Even though the high and very high practical relevance statistics vary over time periods, the figures are so low as to constitute a potential crisis in the DSS discipline. While the low relevance of IS research is well recognized we were surprised by the strength of this adverse finding. We believe that all of the factors identified by Benbasat and Zmud (1999) are in play in DSS research. The relative lack of exposure of academics to contemporary professional practice is a particular problem for DSS.

\begin{tabular}{|l|r|r|r|r|r|r|r|r|}
\hline \multirow{2}{*}{ Practical Relevance } & \multicolumn{2}{|c|}{$1990-1994$} & \multicolumn{2}{|c|}{$1995-1999$} & \multicolumn{2}{|c|}{2000 -2003 } & \multicolumn{2}{c|}{ Total } \\
\cline { 2 - 8 } & No of & \% of & No of & \% of & No of & $\%$ of & No of & $\%$ of \\
& Articles & Period & Articles & Period & Articles & Period & Articles & Sample \\
\hline Very High & 3 & 0.8 & 2 & 0.5 & 5 & 2.3 & 10 & 1.0 \\
\hline
\end{tabular}




\begin{tabular}{|l|r|r|r|r|r|r|r|r|}
\hline High & 33 & 8.7 & 26 & 6.1 & 29 & 13.2 & 88 & 8.6 \\
\hline Medium & 134 & 35.4 & 176 & 41.6 & 96 & 43.8 & 406 & 39.8 \\
\hline Low & 182 & 48.1 & 183 & 43.3 & 74 & 33.8 & 439 & 43.0 \\
\hline None & 26 & 6.9 & 36 & 8.5 & 15 & 6.8 & 77 & 7.5 \\
\hline Total & 378 & 100.0 & 423 & 100.0 & 219 & 100.0 & 1,020 & 100.0 \\
\hline
\end{tabular}

Table 13: Sample by Practical Relevance

Table 14 shows the scores for practical relevance for each type of DSS. Only two DSS types have combined high and very high relevance scores greater than $10 \%$ of papers: executive information systems (33.8\%) and data warehousing (46.2\%). As detailed above, these areas are overwhelmingly dominant in contemporary practice and as a result their high relevance scores are understandable. Unfortunately, only $8.6 \%$ of DSS papers are in these areas. This confirms the significant research and practice disconnect that was hypothesized from the analysis of the DSS 2004 conference proceedings earlier in this paper. For DSS research to be relevant to professional practice, and more importantly influence the direction and nature of professional practice, researchers need to reassess their agendas and focus more on the EIS and data warehousing areas.

\begin{tabular}{|c|c|c|c|c|c|c|c|c|c|c|}
\hline & \multicolumn{2}{|c|}{ Very High } & \multicolumn{2}{|c|}{ High } & \multicolumn{2}{|c|}{ Medium } & \multicolumn{2}{|c|}{ Low } & \multicolumn{2}{|c|}{ None } \\
\hline & $\begin{array}{r}\text { No of } \\
\text { Articles }\end{array}$ & $\begin{array}{l}\% \text { of } \\
\text { Type }\end{array}$ & $\begin{array}{r}\text { No of } \\
\text { Articles }\end{array}$ & $\begin{array}{l}\% \text { of } \\
\text { Type }\end{array}$ & $\begin{array}{r}\text { No of } \\
\text { Articles }\end{array}$ & $\begin{array}{l}\% \text { of } \\
\text { Type }\end{array}$ & $\begin{array}{r}\text { No of } \\
\text { Articles }\end{array}$ & $\begin{array}{l}\% \text { of } \\
\text { Type }\end{array}$ & \begin{tabular}{|r|} 
No of \\
Articles
\end{tabular} & $\begin{array}{l}\% \text { of } \\
\text { Type }\end{array}$ \\
\hline Personal DSS & 5 & 1.4 & 27 & 7.5 & 160 & 44.4 & 148 & 41.1 & 20 & 5.6 \\
\hline Group SS & 1 & 0.3 & 17 & 5.7 & 110 & 36.9 & 136 & 45.6 & 34 & 11.4 \\
\hline EIS (includes BI) & 3 & 4.1 & 22 & 29.7 & 31 & 41.9 & 17 & 23.0 & 1 & 1.4 \\
\hline Data Warehouse & 1 & 7.7 & 5 & 38.5 & 5 & 38.5 & 2 & 15.4 & 0 & 0.0 \\
\hline Intelligent DSS & 0 & 0.0 & 11 & 7.5 & 47 & 32.0 & 81 & 55.1 & 8 & 5.4 \\
\hline KM-based DSS & 0 & 0.0 & 2 & 9.5 & 10 & 47.6 & 8 & 38.1 & 1 & 4.8 \\
\hline Negotiation SS & 0 & 0.0 & 0 & 0.0 & 14 & 34.1 & 18 & 43.9 & 9 & 22.0 \\
\hline Many & 0 & 0.0 & 4 & 6.1 & 29 & 43.9 & 29 & 43.9 & 4 & 6.1 \\
\hline Total & 10 & 1.0 & 88 & 8.6 & 406 & 39.8 & 439 & 43.0 & 77 & 7.5 \\
\hline
\end{tabular}

Table 14: The Practical Relevance of DSS Types 


\section{The Client and User in DSS Research}

As DSS is the area of the information systems discipline that is focused on supporting and improving managerial decision-making, it is important that authors make explicit which type or level of management is addressed by their research. In addition, there are two major roles that managers can play in a DSS: client and user. User is an obvious role. The client is the manager who pays for the system and acts as a champion of the development with other managers. For small systems the client and user are often the same person. This project identified the clients and users in DSS research by evaluating what organisational role was played, or was assumed to be played, by the primary client and primary user in each paper. Table 15 shows the results of the application of this classification to the sample. Of note are the very high figures in the unclear category: $89.3 \%$ for the primary client and $58.6 \%$ for the primary user. This lack of identification of the client or sponsor is particularly noteworthy as research has repeatedly found that executive and operational sponsorship are critical success factors for information systems that support managers (Poon and Wagner, 2001). Further, Poon and Wagner found that effective sponsorship is one of three meta-factors that determine success. The lack of identification of primary clients and users in the sample is a major shortcoming in DSS scholarship.

\begin{tabular}{|c|c|c|c|c|}
\hline & Primary & & Primary & \\
\hline & Frequency & Percentage & Frequency & Percentage \\
\hline Executive & 57 & 5.6 & 73 & 7.2 \\
\hline Non-Executive Manager & 15 & 1.5 & 94 & 9.2 \\
\hline Professional & 24 & 2.4 & 124 & 12.2 \\
\hline Other Knowledge Worker & 13 & 1.3 & 34 & 3.3 \\
\hline Many & - & - & 97 & 9.5 \\
\hline Unclear & 911 & 89.3 & 598 & 58.6 \\
\hline Total & 1.020 & & 1,020 & \\
\hline
\end{tabular}

Table 15: Sample by Primary Client and Primary User

In papers where the clients and users were identified, DSS clients were most likely to be executives and users were most likely to be professionals followed by non-executive managers and executives. This means that professionals are often intermediaries between the IT-based applications and the ultimate decision makers.

\section{Judgement and Decision-making in DSS Research}


Each article was examined to see if any reference theory in judgement and decision-making (JDM) was used. Special care was taken to distinguish between merely citing reference theory in introductory or focussing discussion and using reference theory in the design of the research and interpretation of results. Only the second, integral, use of reference theory was coded in this literature analysis (see Table 16). Surprisingly, $47.2 \%$ of papers did not cite any reference research in judgement and decision-making. Further, the percentage of papers explicitly used judgement and decisionmaking reference research is falling slightly over time. An analysis of the actual references cited revealed that Hebert Simon is the most influential author of reference research in DSS.

\begin{tabular}{|l|r|r|r|r|r|r|r|r|}
\hline & \multicolumn{2}{|c|}{$1990-1994$} & \multicolumn{2}{|c|}{$1995-1999$} & \multicolumn{2}{c|}{2000 -2003 } & \multicolumn{2}{c|}{ Total } \\
\cline { 2 - 9 } & No of & \% of & No of & \% of & No of & \% of & No of & \% of \\
& Articles & Period & Articles & Period & Articles & Period & Articles & Sample \\
\hline JDM theory used & 206 & 54.5 & 219 & 51.8 & 114 & 52.1 & 539 & 52.8 \\
\hline JDM theory not used & 172 & 45.5 & 204 & 48.2 & 105 & 47.9 & 481 & 47.2 \\
\hline Total & 378 & 100.0 & 423 & 100.0 & 219 & 100.0 & 1,020 & 100.0 \\
\hline
\end{tabular}

Table 16: The Use of Judgement and Decision-making Reference Theory

Table 17 shows the number of citations to judgement and decision-making reference research for each type of DSS. Group and negotiation support have the most reference citations, with the current professional mainstream of data warehousing having the poorest grounding.

\begin{tabular}{|l|r|r|r|r|}
\hline Type of DSS & No of & Mean & Standard & Median \\
& Articles & & Deviation & \\
\hline Personal DSS & 360 & 2.24 & 3.83 & 0.00 \\
\hline Group Support Systems & 298 & 2.64 & 3.18 & 2.00 \\
\hline EIS & 74 & 1.59 & 2.87 & 0.00 \\
\hline Data Warehouse & 13 & 0.00 & 0.00 & 0.00 \\
\hline Intelligent DSS & 147 & 0.76 & 1.64 & 0.00 \\
\hline Knowledge Management Based DSS & 21 & 1.29 & 1.90 & 0.00 \\
\hline Negotiation Support Systems & 41 & 2.37 & 2.66 & 1.00 \\
\hline Many & 66 & 2.73 & 4.74 & 1.00 \\
\hline Total & 1,020 & 2.08 & 3.67 & 1.00 \\
\hline
\end{tabular}

Table 17: Number of Cited Judgement and Decision-making References by DSS Type

\section{Summary of Findings}


DSS is an important part of IS research, comprising $15.4 \%$ of the articles published in the 14 major journals in our sample. In addition to this quantitative significance, the field has also made a number of important theoretical contributions to IS including evolutionary systems development, dimensional modelling, and critical success factors. DSS publication has been falling steadily since its peak in 1994 and the current publication rate is at early 1990s levels. Personal DSS and GSS dominate research activity, comprising over two-thirds of all DSS articles. Data warehousing is the least published type of DSS.

Predictably, the journal DSS is the major publishing outlet. US 'Other' journals dominate DSS publishing and there is very low exposure of DSS in European journals. PDSS and GSS are published in a wide selection of journals. EIS/BI largely appears in I\&M, JIT and MISQ. IDSS appears in DS and $D S S$, and NSS appears almost exclusively in GD\&N. KM-based DSS and data warehousing have no obvious outlets.

Around two-thirds of DSS research is empirical, a much higher proportion than IS research. Design science is a major DSS research category, reflecting the field's heritage of the innovative application of IT. Empirical DSS research is overwhelming positivist, and is more dominated by positivism than IS research in general. After design science, laboratory experiments are the most popular investigations. The more modern types of DSS, data warehousing and EIS, have a higher proportion of interpretive research and as a result, interpretivism in DSS is growing from its very low base. Interest in case studies and action research by DSS researchers is relatively low.

The decision support focus of the sample shows a well-balanced mix of development, technology, process and outcome studies. Importantly, DSS researchers have maintained a strong recognition of the importance of the IT artifact in IS research. Studies that test theory are around one quarter of the sample; theory building dominates DSS research, while theory refinement is almost non-existent.

Almost half of DSS papers did not use judgement and decision-making reference research in the design and analysis of their projects. Further, this percentage is falling over time and the most cited reference works are relatively old. GSS and NSS have the best grounding in reference research. 
A major omission in DSS scholarship is the poor identification of the clients and users of the various DSS applications that are the focus of investigation. Almost $90 \%$ of papers failed to identify the principal clients and around $60 \%$ failed to identify the DSS users. Where the clients and users are identified, DSS clients are most likely to be executives, and users are most likely to be professionals followed by non-executive managers and executives.

The analysis of the professional or practical contribution of DSS research shows a field that is facing a crisis of relevance. Half of DSS research was assessed as having low or no practical relevance, and only around $10 \%$ of papers were rated as having high or very high relevance. Only data warehousing and EIS papers have reasonable relevance scores, but less than $10 \%$ of published papers are in this area, with data warehousing at only $1.3 \%$ of the sample. Interestingly, data warehousing and EIS have the highest utilization of interpretive research approaches. The DSS types with the worst relevance scores are Intelligent DSS, NSS and GSS.

\section{Strategies for Improving DSS Research}

The analysis of this paper points to two fundamental issues that need to be addressed by DSS researchers: a crisis of professional relevance and a need to improve the theoretical foundation of studies. These two issues are strongly interrelated.

The low practical relevance of DSS research is in part a symptom of research inertia. Figure 1 showed the evolution of the field into a complex disciplinary structure of partially connected sub-fields. Unfortunately, the earliest sub-fields, now 30 to 40 years old, still dominate quality research publication. It is paradoxical that while DSS publication rate has fallen to early 1990s levels, in practice DSS is one of the only areas of commercial IT that is booming. DSS research is simply focussing on the wrong application areas. As a result CIOs will find little DSS research relevant in planning their IT portfolios. To overcome this disconnect DSS researchers must engage the data warehousing and business intelligence domains. This does not mean a fundamental change of academic activity as many of the theoretical issues that are of interest to PDSS/GSS are also important to, or can be studied in a DW/BI domain. 
Another strategy for improving the relevance of DSS research is to increase the number of case studies, especially interpretive case studies. DSS is lagging behind general IS and the adoption of this research paradigm. Put simply, a field that is so removed from practice needs case study work to ensure that the questions it is addressing are both relevant and important. Interpretive case studies can illuminate areas of contemporary practice in ways that natural science-like studies such as laboratory experiments and surveys cannot (Cavaye, 1996; Eisenhart, 1989). Importantly, they can inspire researchers to focus on issues of current importance and build lasting links between academics and senior professionals.

The analysis of the research approaches in our sample showed a significant amount of design science research. The quality of this work varies greatly with a large number of papers focussing on the reporting a particular implementation. Design science is an important movement in IS research and DSS researchers should be more involved in this style of work, especially as it usually scores highly on relevance assessments. The suggestions of Hevner et al. (2004) should be consulted to help add rigor without compromising the relevance of projects.

The investigation of the judgement and decision-making theory foundation of the papers in our sample shows a relatively poor grounding for the DSS field. DSS researchers need to embrace contemporary research in psychology, management and related fields to provide a stronger theoretical basis for projects. DSS seems to have an over reliance on the style behavioural decision theory developed by Herbert Simon. We believe that a broader theoretical foundation may also make DSS research more relevant as the use of a narrow base of reference theory may have acted to overly constrain what projects have been thought to be feasible and important. A broader foundation may take DSS research into a role of shaping practice rather than ignoring it.

In conclusion, DSS, as an important field of information systems research and practice, is at the crossroads; its future is both bright and troubled. Its share of IS research is declining but in industry it is growing significantly despite the IT downturn. We believe that left unchanged, the current agendas 
of DSS researchers will lead the field to irrelevance. We plan to revisit this analysis in a number of years and, hopefully, we will find this important sub-field of IS resurgent.

\section{References}

Ackoff, R.L. (1967) Management misinformation systems. Management Science, 14(4), 147-156.

Alavi, M. and Carlson, P. (1992) A review of MIS research and disciplinary development. Journal of Management Information Systems, 8(4), 45-62.

Alavi, M. and Joachimsthaler, E.A. (1992) Revisiting DSS Implementation research: A meta-analysis of the literature and suggestions for researchers. MIS Quarterly, 16(1), 95-116.

Alavi, M. and Leidner, D.E. (2001) Review: Knowledge management and knowledge management systems: conceptual foundations and research issues. MIS Quarterly, 25(1), 107-136.

Alter, S.L. (1980) Decision Support Systems: Current Practice and Continuing Challenges (Addison-Wesley, Reading, MA).

Anthony, R.N. (1965) Planning and Control Systems: A Framework for Analysis (Harvard University Graduate School of Business Administration, Cambridge, MA).

Arnott, D. (2004) Decision support systems evolution: Framework, case study and research agenda. European Journal of Information Systems, 13(4), 247-259.

Arrow, K.J. (1951) Social Choice and Individual Values (Wiley, New York).

Basu, A. and Blanning, R.W. (1994) Metagraphs: A tool for modelling decision support systems. Management Science, 40(12), 1579-1600.

Benbasat, I. and Nault, B. (1990) An evaluation of empirical research in managerial support systems. Decision Support Systems, 6, 203-226. 
Benbasat, I. and Zmud, R.W. (1999) Empirical research in information systems: The question of relevance. MIS Quarterly, 23(1), 3-16.

Benbunan-Fich, R., Hiltz, S.R. and Turoff, M. (2002) A comparative content analysis of face-to-face vs. asynchronous group decision making. Decision Support Systems, 34, 457-469.

Bidgoli, H. (1998) Intelligent Management Support Systems (Greenwood, Westport CT).

Bottom, W.P. and Paese, P.W. (1999) Judgement accuracy and the asymmetric cost of errors in distributive bargaining. Group Decision and Negotiation, 8, 349-364.

Bui, T. and Jarke, M. (1986) Communication design for Co-op: A group decision support system. ACM Transaction on Office Information Systems, 4(2), 81-103.

Carlsson, S., Brezillon, P., Humphreys, P., Lunberg, B.G. McCosh, A. and Rajkovic, V. (Eds.) (2000) Proceedings of IFIP TC8/WG8.3 International Conference on Decision Support Through Knowledge Management. Stockholm, Sweden: Stockholm University/Royal Institute of Technology, Sweden.

Carlsson, S.A. and Lundberg, B.G. (2000) Preface and introduction. Proceedings of IFIP TC8/WG8.3 International Conference on Decision Support Through Knowledge Management. Stockholm, Sweden: Stockholm University/Royal Institute of Technology, Sweden.

Cavaye, A.L.M. (1996) Case study research: A multi-faceted research approach for IS. Information Systems Journal, 6, 227-242.

Chaudhury, A. (1995) A process perspective to designing individual negotiation support systems. Group Decision and Negotiation, 4(6), 525-548.

Chen, M. (1995) A model-driven approach to accessing managerial information: The development of a repository-based executive information system. Journal of Management Information Systems, 11(4), 33-63.

Chen, W.S. and Hirschheim, R. (2004) A paradigmatic and methodological examination of information systems research from 1991 to 2001. Information Systems Journal, 14, 197-235. 
Codd, E.F., Codd, S.B. and Salley, C.T. (1993) Providing on-line analytical processing (OLAP) to user-analysts: An IT mandate (Unpublished Manuscript). E.F. Codd and Associates.

Cooper, B.L., Watson, H.J., Wixom, B.H. and Goodhue, D.L. (2000) Data warehousing supports corporate strategy at First American Corporation. MIS Quarterly, 24(4), 547-567.

Craig, R.S., Vivona, J.A. and Bercovitch, D. (1999) Microsoft Data Warehousing (Wiley, New York).

Datta, A. and Thomas, H. (1999) The cube data model: A conceptual model and algebra for on-line analytical processing in data warehouses. Decision Support Systems, 27, 289-301.

Davison, R. (1999) An instrument for measuring meeting success Revalidation and modification. Information and Management, 36, 321-328.

Dearden, J. (1972) MIS is a mirage. Harvard Business Review, 50(1), 90-99.

Dennis, A.R., George, J.F., Jessup, L.M., Nunamaker, J.F. Jr. and Vogel, D.R. (1988) Information technology to support group meetings. MIS Quarterly, 12(4), 591-624.

DeSanctis, G. and Gallupe, R.B. (1985) Group decision support systems: A new frontier. Data Base, 16(2), 3-10.

DeSanctis, G. and Gallupe, R.B. (1987) A foundation for the study of group decision support systems Management Science, 33(5), 589-609.

Dennis, A.R. and Gallupe, R.B. (1993) A history of group support systems empirical research: Lessons learned and future directions. In L.M. Jessup and J.S. Valacich (Eds.) Group Support Systems: New Perspectives. (New York, Macmillan), Chapter 3.

Devlin, B.A. and Murphy, P.T. (1988) An architecture for a business and information system. IBM Systems Journal, 27(1), 60-81.

Doukidis, G.I., Land, F. and Miller, G. (1989) Knowledge Based Management Support Systems (Ellis Horwood, Chichester).

Dubin, R. (1978) Theory Building (The Free Press, New York). 
Eisenhart. K.M. (1989) Building theories from case study research. Academy of Management Review, 14, 532-550.

Eom, H.B. and Lee, S.M. (1990) A survey of decision support system applications (1971-1988). Interfaces, 20, 65-79.

Eom, S.B. (1995) Decision Support Systems Research: Reference Disciplines and a Cumulative Tradition. Omega: The International Journal of Management Science, 23(5), 511-523.

Eom, S.B. (1996) Mapping the intellectual structure of research in decision support systems through author cocitation analysis (1971-1993). Decision Support Systems, 16(4), 315-338

Eom, S.B. (1999) Decision Support Systems Research: Current State and Trends. Industrial Management and Data Systems, 99(5), 213-220.

Eom, S.B. and Lee, S.M. (1993) Leading Universities and Most Influential Contributors in DSS Research: A Citation Analysis. Decision Support Systems, 9(3), 237-244.

Fitzgerald, B. (2000) System development methodologies: The problem of tenses. Information Technology and People, 13(3), 13-22.

Fitzgerald, G. (1992) Executive information systems and their development in the U.K.: A research study. International Information Systems, 1(2), 1-35.

Fraser, N.M. and Hippel, K.W. (1984) Conflict Analysis: Models and Resolution (North Holland, Amsterdam).

Galliers, R.D. (1992) Choosing information systems research approaches. In R.D. Galliers (Ed.), Information Systems Research: Issues, Methods and Practical Guidelines (Blackwell Scientific, London), 144-162.

Galliers, R.D. (1994) Relevance and rigour in information systems research: Some personal reflections on issues facing the information systems research community. In B.C Glasson, I.T. Hawryszkiewycz, B.A. Underwood and R. Weber (Eds.). Business process re-engineering: Information systems opportunities and challenges (Elsevier North-Holland, Amsterdam), 93-101. 
Gillenson, M. L. and Stutz, J. D. (1991) Academic issues in MIS: Journals and books. MIS Quarterly, 15(4), 447-452.

Gorry, G.A. and Scott Morton, M.S. (1971) A framework for management information systems. Sloan Management Review, 13(1), 1-22.

Gray, P., Aronofsky, J.S., Helmer, O., Kane, G.R. and Perkins, T.E. (1981) The SMU decision room project. Proceedings of DSS-81: The First International Conference on Decision Support Systems, Atlanta, Georgia, June 8-10.

Guba, E.G. and Lincoln, Y.S. (1994) Competing paradigms in qualitative research. In N.K. Denzin and Y.S. Lincoln (Eds.). Handbook of Qualitative Research (Sage Publications, Thousand Oaks, CA), 105-117.

Hardgrave, B. C. and Walstrom, K. A. (1997) Forums for MIS scholars. Communications of the ACM, 40(11), 119-124.

Hevner, A.R., March, S. T., Park, J. and Ram, S. (2004) Design science in information systems research. MIS Quarterly, 28(1), 75-106.

Hirschheim, R. (1992) Information systems epistemology: An historical perspective. In R. Galliers (Ed.), Information systems research: Issues, methods and practical guidelines (Blackwell Scientific Publications, Oxford), 28-60.

Holsapple, C., Johnson, L., Manakyan, H. and Tanner, J. (1994) Business computing research journals: A normalized citation analysis. Journal of Management Information Systems, 11(1), $131-140$.

Huber, G.P. (1984) Issues in the design of group decision support systems. MIS Quarterly, 8(3), 195204.

Iivari, J. (1991) A paradigmatic analysis of contemporary schools of IS development. European Journal of Information Systems, 1(4), 249-272.

Inmon, W. and Hackathorn, R. (1994) Using the Data Warehouse. (John Wiley and Sons, New York). 
Jarke, M., Jelassi, M.T. and Shakun, M.F. (1987) MEDIATOR: Toward a negotiation support system. European Journal of Operations Research, 31(3), 314-334.

Jelassi, M.T., Kersten, G. and Zionts, S. (1990) An introduction to group decision and negotiation support. In M.T.Jelassi, G. Kersten, and S. Zionts (Eds.) Readings in Multiple Criteria Decision Making. (Springer-Verlag: Berlin).

Kaplan, R.S. and Norton, D.P. (1996) The Balanced Scorecard: Translating Strategy into Action. (Harvard Business School Press, Cambridge, MA).

Karim, A.S., Hershauer, J.C. and Perkins, W.C. (1998) A simulation of partial information use in decision making: Implications for DSS design. Decision Sciences, 29(1), 53-85.

Keen, P.G.W. and Gambino, A.J. (1983) In J.L. Bennett (Ed.) Readings in Decision Support Systems (Addison-Wesley, Reading, MA).

Keen, P.G.W. and Scott Morton, M.S. (1978) Decision Support Systems: An Organisational Perspective. (Addison-Wesley, Reading, MA).

Keen, P.G.W. (1997) Let's focus on action not information: Information is a misleading and damaging IS term. Computerworld, 31(46), November 17, 100.

Kendall, K.E. (1997) The significance of information systems research on emerging technologies: seven information technologies that promise to improve managerial effectiveness. Decision Sciences, 28(4), 775-792.

Kersten, G.E. (1987) On two roles decision support can play in negotiation. Information Processing and Management, 23(5), 605-614.

Kersten, G.E. and Shapiro, T. (1986) Generalized approach to modelling negotiation. European Journal of Operations Research, 26(1), 142-149.

Kimball, R. (1996) The Data Warehousing Toolkit. (John Wiley and Sons, New York).

Kimball, R., Reeves, L., Ross, M. and Thornwaite, W. (1998) The Data Warehousing Lifecycle Toolkit. (John Wiley and Sons, New York). 
King, J.L. and Lyytinen, K. (2004) Reach and grasp. MIS Quarterly, 28(4), 539-551.

Kock, N. (1998) Can communication medium limitations foster better group outcomes? An action research study. Information and Management, 34, 295-305.

Konsynski, B.R., Kottemann, J.E., Nunamaker, J.F., Jr. and Stott, J.W. (1985) PLEXSYS-84: An integrated development environment for information systems. Journal of Management Information Systems, 1(3), 64-104.

Kraemer, K.L. and King, J.L. (1988) Computer-based systems for cooperative work and group decision making. ACM Computing Surveys, 20(2), 115-146.

Kuhn, H.W. and Tucker, A.W. (Eds.) (1950) Contributions to the Theory of Games (Annals of Mathematics Study No. 24). (Princeton University Press, Princeton).

Lewis, L.F., Keleman, K.S. and Garcia, J.E. (1996) Possible barriers and challenges to the adoption of group support systems. Group Decision and Negotiation, 6(2), 189-194.

Linton, J.D. and Johnston, D.A. (2000) A decision support system for planning remanufacturing at Nortel Networks. Interfaces, 30(6), 17-31.

Lowry, P.B., Romans, D. and Curtis, A. (2004) Global journal prestige and supporting disciplines: A scientometic study of information systems journals. Journal of the Association for Information Systems, 5(2), 29-77.

Malone, T.W. and Crowston, K. (1994) The interdisciplinary study of coordination. ACM Computing Surveys, 26(1), 87-119.

McCosh, A.M. (2004) Keynote Address. The 2004 IFIP International Conference on Decision Support Systems. (IFIP, Prato, Italy).

McCosh, A.M. and Scott Morton, M.S. (1978) Management Decision Support Systems (Macmillan, London).

McGrath, J.E. and Hollingshead, A.B. (1993) Putting the "group" back in group support systems" Some theoretical issues about dynamic processes in groups with technological enhancements. In 
L.M. Jessup and J.S. Valacich (Eds.) Group Support Systems: New Perspectives. (Macmillan: New York), Chapter 4.

Meador, C.L. and Ness, D.N. (1974) Decision support systems: An approach to corporate planning. Sloan Management Review, 15(2), 51-68.

Meredith, R., Shanks, G., Arnott, D. and Carlsson, S (Eds.) Decision Support in a Complex and Uncertain World: Proceedings of the 2004 IFIP International Conference on Decision Support Systems. (IFIP, Prato, Italy).

Mills, K. (2004) Raiding the data bank. The Australian IT Business, October 16, 1-4.

Mintzberg, H. (1977) Impediments to the use of managerial information (National Association of Accountants, New York and the Society of Management Accountants of Canada, Ontario, Canada).

Morris, H.D., Graham, S., Andersen, P., Moser, K.D., Carr, M., Blumstein, R., Vesset, D. and Martinez, N. (2003) Financial Impact of Business Analytics: The Key Findings. IDC White Paper, January, 23.

Mylonopoulos, N.A. and Theoharakis, V. (2001) On-Site: Global perceptions of IS journals. Communications of the ACM, 44(9), 29-33.

Nandhakumar, J. (1996) Executive information system development: A case study of a manufacturing company. Journal of Information Technology, 11, 199-209.

Nash, J. (1950) The bargaining problem. Econometrica, 18(2), 155-162.

Nash, J. (1953) Two-person cooperative games. Econometrica, 21(1), 128-140.

NCR (1998) How to Build a Data Warehouse, Data Warehousing Workshop: Module 4. [Course notes] NCR Corporation.

Nunamaker, J.F., Jr., Dennis, A.R., Valacich, J.S., Vogel, D.R. and George, J.F. (1991) Electronic meeting systems to support group work. Communications of the ACM, 34(7), 40-61. 
Nurmi, H. (2001) Resolving group choice paradoxes using probabilistic and fuzzy concepts. Group Decision and Negotiation, 10, 177-198.

Orlikowski, W.J. and Baroudi, J.J. (1991) Studying information technology in organizations: Research approaches and assumptions. Information Systems Research, 2, 1-28.

Pearson, J.M. and Shim, J.P. (1994) An empirical investigation into decision support systems capabilities: A proposed taxonomy. Information and Management, 27(1), 45-57.

Pervan, G.P. (1998) A review of research in group support systems: Leaders, approaches and directions. Decision Support Systems, 23(2), 149-159.

Pervan, G.P. and Atkinson, D.J. (1995) GDSS research: An overview and historical analysis. Group Decision and Negotiation, 4(6), 475-485.

Poon, P. and Wagner, C. (2001) Critical success factors revisited: Success and failure cases of information systems for senior executives. Decision Support Systems, 30, 393-418.

Powell, P.L. and Johnson, J.E.V. (1995) Gender and DSS design: The research implications. Decision Support Systems, 14, 27-58.

Press, L. (1992) Lotus Notes (groupware) in context. Journal of Organizational Computing, 2, 315 320.

Raiffa, H. (1982) The Art and Science of Negotiation. (Belknap Press, Cambridge, MA).

Rangaswamy, A. and Shell, G.R. (1997) Using computers to realize joint gains in negotiations: Toward an 'Electronic Bargaining Table'. Management Science, 43(8), 1147-1163.

Robey, D., Boudrea, M-C. and Rose, G.M. (2000) Information technology and organizational learning: a review and assessment of research. Accounting, Management and Information Technology, 10, 125-155.

Rockart, J.F. (1979) Chief executives define their own data needs. Harvard Business Review. 57, March-April, 81-93. 
Rockart J.F. and DeLong D.W. (1988) Executive Support Systems: The Emergence of Top Management Computer Use, (Dow Jones-Irwin, Illinois).

Rubinstein, A. (1982) Perfect equilibrium in a bargaining model. Econometrica, 50, 97-109.

Saunders, C. (1998) The role of business in IS research. Information Resource Management Journal, Winter, 11(1), 4-6.

Scott Morton, M.S. (1971) Management Decision Systems: Computer-Based Support for Decision Making. (Harvard University, Boston, MA).

Shim, J.P., Warkentin, M., Courtney, J.F., Power, D.J., Sharda, R. and Carlson, C. (2002) Past, present, and future of decision support technology. Decision Support Systems, 33, 111-126.

Silver, M.S. (1991) Systems that Support Decision Makers: Description and Analysis. (John Wiley and Sons, New York).

Simon, H.A. (1977) The new science of management decision (rev. ed.). Englewood Cliffs, NJ: Prentice-Hall. (Original work published 1960).

Sprague, R.H. Jr, and Carlson, E.D. (1982) Building Effective Decision Support Systems. (Prentice Hall, Englewood Cliffs, NJ).

Stanek, S, and Sroka, H. (2001) Building creativity into OSS design framework. Journal of Decision Systems, 10(3-4), 339-378.

Stohr, E.A. and Konsynski, B.R. (Eds.). (1992) Information Systems and Decision Processes. (IEEE Computer Society Press, Los Alamitos, CA).

Todd, P. and Benbasat, I. (1991) An experimental investigation of the impact of computer based decision aids on decision making strategies. Information Systems Research, 2(2), 87-115.

Tolliver, E.M. (1971) Myths of automated management systems. Journal of Systems Management, 22(3), 29-32.

Turban, E., Aronson, J.E. and Liang, T-P. (2005) Decision Support Systems and Intelligent Systems (7th ed.). (Pearson Education, Upper Saddle River, NJ). 
Vandenbosch, B. and Huff, S.L. (1997) Searching and scanning: How executives obtain information from executive information systems. MIS Quarterly, 21(1), 81-107.

Von Neumann, J., and Morgenstern, O. (1947) Theory of Games and Economic Behaviour. (Princeton University Press, Princeton).

Wagner, G.R., Wynne, B.E., and Mennecke, B.E. (1993) Group support systems facilities and software. In L.M. Jessup and J.S. Valacich (Eds.) Group Support Systems: New Perspectives. (Macmillan, New York), Chapter 2.

Walsham, G. (1995a) Interpretive case studies in IS research: Nature and method. European Journal of Information Systems, 4, 74-81.

Walsham, G. (1995b) The emergence of interpretivism in IS research. Information Systems Research, 6(4), 376-394.

Walstrom, K. A., Hardgrave, B. C. and Wilson, R. L. (1995) Forums for Management Information Systems scholars. Communications of the ACM, 38(3), 93-107.

Weber, R. (1987) Towards a theory of artifacts: A paradigmatic base for information systems research. Journal of Information Systems, 1, 3-20.

Webster, J. and Watson, R.T. (2002) Analyzing the past to prepare for the future: Writing a literature review. MIS Quarterly, 26(2), xiii-xxiii.

Whitman, M.E., Hendrickson, A.R., Townsend, A.M. (1999) Research Commentary. Academic rewards for teaching, research and service: Data and discourse. Information Systems Research, 10(2), 99-109.

Wixom, B.H. and Watson, H.J. (2001) An empirical investigation of the factors affecting data warehousing success. MIS Quarterly, 23(1), 17-41.

Wood, J.R.G. and Wood-Harper, A.T. (1993) Information technology in support of individual decision-making. Journal of Information Systems, 3, 85-101. 
Yin, R.K. (1994) Case Study Research: Design and Methods (2 ${ }^{\text {nd }}$ edn.). (Sage Publications, Newbury Park, CA).

\section{Appendix: Article Coding Protocol}

\section{RESEARCH TYPE}

\begin{tabular}{|c|c|c|c|c|c|c|}
\hline R1. Dominant & Theory & Theory & Theory & \multicolumn{2}{|c|}{ Unclear } & \\
\hline Research Stage: & $\begin{array}{l}\text { Building } \\
1\end{array}$ & $\begin{array}{c}\text { Testing } \\
2\end{array}$ & $\begin{array}{l}\text { Refinement } \\
3\end{array}$ & & & \\
\hline R2. Epistemology: & $\begin{array}{c}\text { Positivist } \\
1\end{array}$ & $\begin{array}{c}\text { Interpretivist } \\
2\end{array}$ & $\begin{array}{c}\text { Critical } \\
3\end{array}$ & $\begin{array}{c}\text { Mixed } \\
4\end{array}$ & $\begin{array}{c}\text { Unclear } \\
5\end{array}$ & $\begin{array}{c}\text { N/A } \\
6\end{array}$ \\
\hline
\end{tabular}

R3. Article Type (coded according to Table 7) R4. Comments:

\section{DSS FACTORS}

D1. What type of DSS is the paper addressing?

$\begin{array}{ll}\text { 1. Personal DSS (includes modelling and analytics) } & \text { 2. Group support systems }\end{array}$

3. EIS (includes BI, OLAP and enterprise wide reporting)4. Data warehouse (includes data marts)

5. Intelligent DSS (includes knowledge-based DSS) 6. Knowledge management-based DSS

7. Many

8. Negotiation support systems

D2. What organizational level is addressed?
1. Individual
3. Group
4. Department
5. Division
6. Organization
7. Unclear

2. Small number of independent managers

D3. What is the decision support focus of the paper?
1. Development
2. Technology
3. Decision outcome/organizational impact
4. Decision process
5. Many
6. Unclear

D4. What is the practical relevance of the paper?
1. Very High
2. High
3. Medium
4. Low
5. None

D5. Comments:

\section{JUDGEMENT and DECISION MAKING FACTORS}

$\mathrm{J} 1$. Who is the primary client?

$\begin{array}{cc}\text { Executive } & \begin{array}{c}\text { Non-executive } \\ \text { Manager }\end{array} \\ 1 & 2\end{array}$

J2. What is the primary user's functional area?

J3. Who is the primary user?
Professional

3
Other

4 5
Professional
Executive Non-executive
Manager
Other Unclear Many 
J4. Is judgement and decision-making reference research cited?

Yes No

J5.

If cited what reference theories? (author/date citations)

What general approach to decision-making is used?

J6.

$$
\text { Descriptive }
$$$$
1
$$

$\mathrm{J} 7$.

$$
\text { Economic }
$$

$$
1
$$

\section{Prescriptive 2}

Behavioural 2
Unclear 3

Unclear

J8. Is a phase model of decision-making used? Yes No

J9. If yes, then which

J10. Comments: 